\title{
Ferulic Acid and Salicylic Acid Foliar Treatments Reduce Short-Term Salt Stress in Chinese Cabbage by Increasing Phenolic Compounds Accumulation and Photosynthetic Performance
}

\author{
Ida Linić ${ }^{1,2}$, Selma Mlinarić ${ }^{3}\left(\mathbb{D}\right.$, Lidija Brkljačić $^{4}$, Iva Pavlović ${ }^{1}$ (D), Ana Smolko ${ }^{1}$ (D) \\ and Branka Salopek-Sondi ${ }^{1, *(D)}$
}

1 Department for Molecular Biology, Ruđer Bošković Institute, 10000 Zagreb, Croatia; ida.linic@irb.hr (I.L.); iva.pavlovic@irb.hr (I.P.); ana.smolko@irb.hr (A.S.)

2 Department of Agriculture and Nutrition, Institute of Agriculture and Tourism, 52440 Poreč, Croatia

3 Department of Biology, Josip Juraj Strossmayer University of Osijek, 31000 Osijek, Croatia; smlinaric@biologija.unios.hr

4 Department for Organic Chemistry and Biochemistry, Ruđer Bošković Institute, 10000 Zagreb, Croatia; lidija.brkljacic@irb.hr

* Correspondence: salopek@irb.hr; Tel.: +385-1-4561-143

Citation: Linić, I.; Mlinarić, S.; Brkljačić, L.; Pavlović, I.; Smolko, A.; Salopek-Sondi, B. Ferulic Acid and Salicylic Acid Foliar Treatments Reduce Short-Term Salt Stress in Chinese Cabbage by Increasing Phenolic Compounds Accumulation and Photosynthetic Performance. Plants 2021, 10, 2346. https:// doi.org/10.3390/plants10112346

Academic Editor:

Domenico Trombetta

Received: 29 September 2021

Accepted: 27 October 2021

Published: 29 October 2021

Publisher's Note: MDPI stays neutral with regard to jurisdictional claims in published maps and institutional affiliations.

Copyright: (c) 2021 by the authors. Licensee MDPI, Basel, Switzerland. This article is an open access article distributed under the terms and conditions of the Creative Commons Attribution (CC BY) license (https:/ / creativecommons.org/licenses/by/ $4.0 /$ )
Abstract: Salinity stress is one of the most damaging abiotic stresses to plants, causing disturbances in physiological, biochemical, and metabolic processes. The exogenous application of natural metabolites is a useful strategy to reduce the adverse effects of stress on crops. We investigated the effect of foliar application of salicylic acid (SA) and ferulic acid (FA) (10-100 $\mu \mathrm{M})$ on short-term salt-stressed $(150 \mathrm{mM} \mathrm{NaCl}, 72 \mathrm{~h})$ Chinese cabbage plants. Subsequently, proline level, photosynthetic performance, phenolic metabolites with special focus on selected phenolic acids (sinapic acid (SiA), FA, SA), flavonoids (quercetin (QUE), kaempferol (KAE)), and antioxidant activity were investigated in saltstressed and phenolic acid-treated plants compared with the corresponding controls. Salt stress caused a significant increase in SA and proline contents, a decrease in phenolic compounds, antioxidant activity, and photosynthetic performance, especially due to the impairment of PSI function. SA and FA treatments, with a concentration of $10 \mu \mathrm{M}$, had attenuated effects on salt-stressed plants, causing a decrease in proline and SA level, and indicating that the plants suffered less metabolic disturbance. Polyphenolic compounds, especially FA, SiA, KAE, and QUE, were increased in FA and SA treatments in salt-stressed plants. Consequently, antioxidant activities were increased, and photosynthetic performances were improved. FA resulted in a better ameliorative effect on salt stress compared to SA.

Keywords: Brassica rapa ssp. pekinensis; phenolic compounds; foliar treatment; photosynthetic performance; salicylic acid; ferulic acid; salt stress

\section{Introduction}

Global warming and current climate changes are serious threats to agricultural production and biodiversity worldwide [1]. Among abiotic stresses, salt stress is one of the most damaging for plants because it is a complex stress consisting of ionic stress caused by toxic ion concentrations (mainly $\mathrm{Na}^{+}$), osmotic stress caused by the associated decreased water uptake, and oxidative stress caused by the increase in reactive oxygen species levels (ROS) [2]. Increased soil salinity is caused by natural processes (such as mineral weathering or by the gradual retreat of an ocean) but also by various human activities mainly related to agricultural practices (especially soil irrigation, fertilization, etc.). It is estimated that about $6 \%$ of all land areas are affected by salt, with about $22 \%$ of cultivated fields and $33 \%$ of irrigated fields used for agriculture. The problem is particularly severe in Mediterranean, semi-arid, and arid areas and is predicted to be more drastic in the future [3]. 
Salinity stress causes disturbances in physiological, biochemical, and metabolic processes important for plant growth and development. It can alter gene transcription, primary and secondary metabolism, cause an increase in ROS level, affect ion homeostasis, damage photosynthetic apparatus and reduce photosynthetic output, alter membrane permeability, inhibit growth and biomass accumulation, and consequently leads to a significant reduction in crop yield [4].

Brassica vegetables are among the economically important crops grown worldwide that can be seriously affected by salt stress. All developmental stages of Brassica species, from seed germination to seedlings and adult plants, may be threatened by elevated salinity, depending on the natural salt tolerance of the species, duration of stress, and salt concentration [2]. It has been reported that salt tolerance depends on the ploidy of the Brassica genome. Accordingly, Brassica species that are amphitetraploid, such as B. juncea, $B$. carinata, and $B$. napus, are relatively more tolerant to salt stress compared to their diploid parents B. campestris, B. nigra, and B. oleracea [5]. However, there is some variation in salt tolerance within species (amphitetraploid or diploid) and even within cultivars of the same species $[6,7]$.

Salt stress response in the Brassica species and plants, in general, is a complex trait regulated by many factors (plant hormones, antioxidants, such as polyphenolic compounds, osmoprotectants, etc.) [2,8]. Polyphenols are a diverse group of specialized metabolites that are generally recognized as molecules involved in stress protection in plants, mainly because of their antioxidant activity [9]. It is reported that plants with increased phenolic content under abiotic stress usually show better adaptability to limiting environmental conditions (salinity, drought, temperature, heavy metals, etc.) [10].

Selection and breeding of salt-tolerant species and strategies to increase salinity tolerance of sensitive species are of great importance and agronomic interest. In this regard, there are genetically-based strategies, from classical crossing to modern transgene manipulations and genome editing, which are more or less time-consuming methods. In addition to genetic strategies, exogenous application of various agents, such as natural metabolites or synthetic compounds, has been shown to be an excellent way to decrease the adverse effects of salt stress in several important agricultural crops without altering their genome [4]. The exogenous application of numerous natural bioactive molecules (osmoprotectants, plant hormones, antioxidants, etc.) has been found to be useful in neutralizing the deleterious effects of salt stress in various plants [11]. Here we are particularly interested in the application of phenolic acids and their potential mitigating effect on salt stress. The application of SA has been reported to have great agronomic potential in improving the stress response of various agriculturally important crops (barley, maize, sunflower, wheat, bean, strawberry, chamomile etc.) [12]. Several beneficial effects of SA have been reported for plants under salt stress: the alleviation or decrease in photosynthetic pigments and photosynthetic performance, maintenance of membrane integrity, promotion of accumulation of $\mathrm{ABA}$ and proline, decrease in lipid peroxidation and membrane permeability, decrease in $\mathrm{Na}^{+}$content and increase in $\mathrm{K}^{+}$concentration, etc. [12].

Aside from SA, a better response of wheat seedlings was obtained in salt stress after treatment with sinapic acid, caffeic acid, ferulic acid, and $p$-coumaric acid [13]. In addition, the application of vanillic acid can decrease the negative effects of salt stress in tomato plants [14], caffeic acid protects cucumber from chilling stress [15], and treatment with ellagic acid accelerated the germination and seedling growth of chickpea under osmotic stress conditions [16]. All these phenolic acids were reported to improve plant antioxidant status by increasing the activities of antioxidant enzymes and the accumulation of nonenzymatic antioxidants.

Our recent comparative studies on three Brassica crops (kale, white cabbage, and Chinese cabbage) showed a positive correlation of phenolic acids and salinity tolerance and clearly identified kale as the most tolerant, then white cabbage as moderately tolerant, and finally Chinese cabbage as the most sensitive species [17]. We showed that the more tolerant kale and white cabbage have significantly higher levels of phenolic acids, especially hydrox- 
ycinnamic acids (mainly sinapic acid (SiA), ferulic acid (FA), caffeic acid (CaA), 4-coumaric acid ( $\mathrm{pCoA})$ ) and suffer less from metabolic disorders under salt stress than the more sensitive Chinese cabbage. Therefore, our aim was to investigate if the foliar application of selected phenolic acids may diminish the adverse effect of short-term salt stress (72 h) in Chinese cabbage. For this purpose, solutions of salicylic acid (representative of hydroxybenzoic acids and plant stress hormone) and ferulic acid (representative of hydroxycinnamic acids) were sprayed at concentrations of 10-100 $\mu \mathrm{M}$ onto leaves of onemonth-old Chinese cabbages treated with $150 \mathrm{mM} \mathrm{NaCl}$. Stress levels, photosynthetic performance, phenolic metabolites, and antioxidant activity were then examined under the control and salt stress conditions $(150 \mathrm{mM})$.

\section{Results}

One-month-old plantlets of Chinese cabbage were foliar-treated by a spray applicator with FA and SA in the concentration range of $10-100 \mu \mathrm{M}$, approximately $0.5 \mathrm{~mL}$ per plant per treatment, and their effects were investigated under $\mathrm{NaCl}$ stress conditions $(150 \mathrm{mM}$, in the time period of $72 \mathrm{~h}$ ) compared to untreated controls. Short-time salinity stress caused visible plant dehydration that was less prominent in plants treated with phenolic acids. Changes in growth parameters were not observable under the short experimental period $(72 \mathrm{~h})$.

To access biochemical changes, we measured proline as the reliable stress marker, groups of polyphenolic compounds (total polyphenols, total phenolic acids, total flavonoids and total flavanols), as well as the most abundant phenolic compounds well known as powerful antioxidants in Brassicaceae (ferulic acid (FA), sinapic acid ( $\mathrm{SiA}$ ), salicylic acid (SA), kaempferol (KAE), and quercetin (QUE) and antioxidant activities. Furthermore, selected photosynthetic parameters were screened by chlorophyll $a$ fluorescence.

\subsection{Proline Level}

To assess the plant stress response to $\mathrm{NaCl}$-treated plants and identify the effect of phenolic acids (FA and SA) on the stressed plants, we analyzed proline as a salt stress marker in eight sets of experimental plants (Figure 1).

Phenolic acid treatments had no significant effect on proline content in plants grown under non-saline conditions compared to untreated controls. This suggests that phenolic acids per se did not cause stress in treated plants. Under salt stress, proline contents increased significantly (18 and 23-fold in FA and SA experimental sets, respectively) compared to the unstressed controls (Figure 1). Treatments with both phenolic acids (FA and SA) at a concentration of $10 \mu \mathrm{M}$ caused a significant reduction in proline content. Proline content was reduced about five-fold in foliar treatments compared with content in saltstressed, untreated plants. The application of higher concentrations (50 and $100 \mu \mathrm{M}$ ) of both phenolic acids resulted in increased proline content. The increase in proline was more pronounced in FA than in SA treatments (50 and $100 \mu \mathrm{M}$ ) compared to $10 \mu \mathrm{M}$ concentration and untreated plants. 

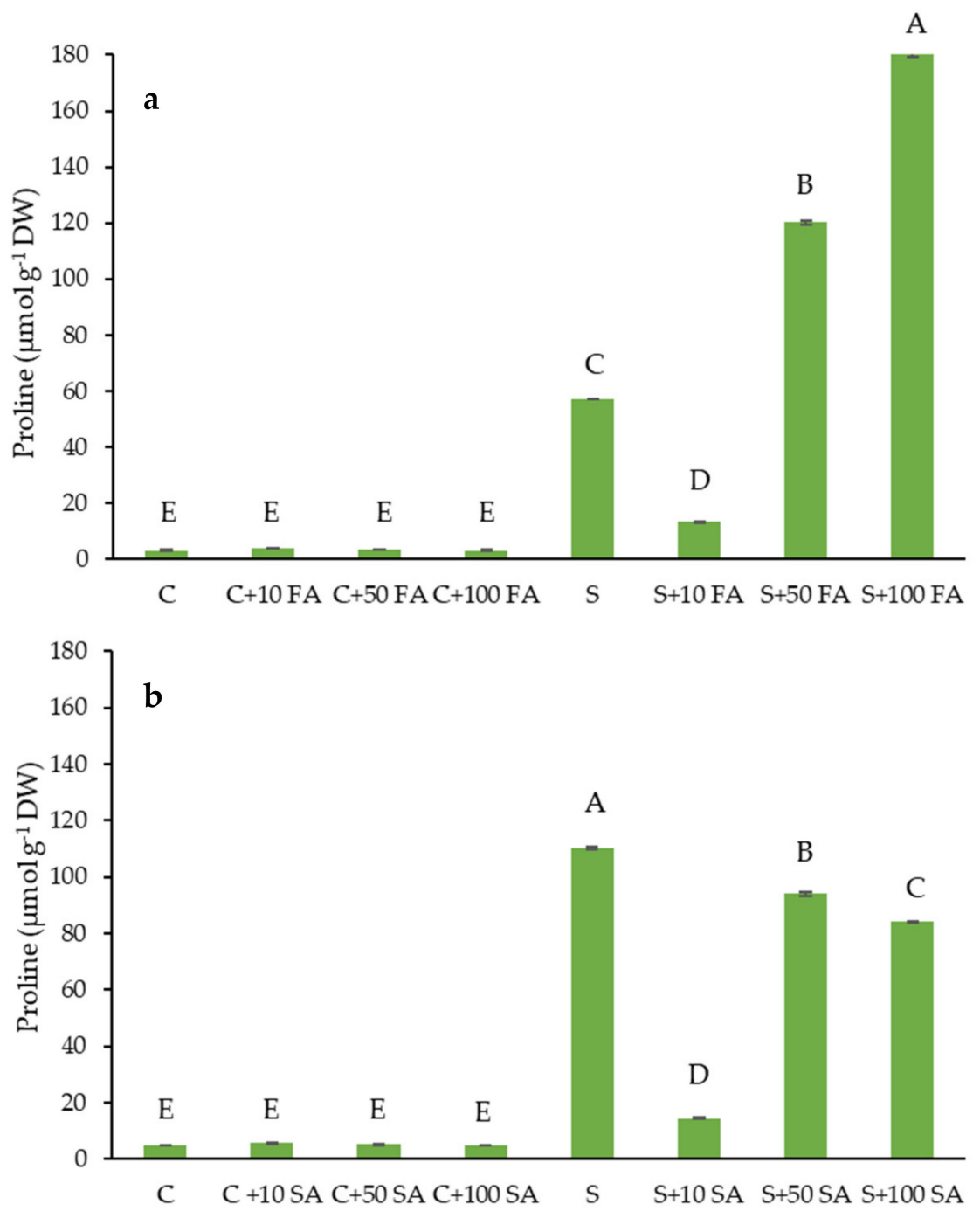

Figure 1. Effect of foliar treatments of B. rapa plants with: (a) ferulic acid (FA) and (b) salicylic acid (SA) at concentrations 10,50 , and $100 \mu \mathrm{M}$ on proline content under salt treatment $(\mathrm{S}, 150 \mathrm{mM} \mathrm{NaCl})$ compared to untreated control $(C)$, for $72 \mathrm{~h}$. Data are mean $\pm \mathrm{sd}(\mathrm{n}=3)$. Proline is expressed as $\mu \mathrm{mol}$ per $\mathrm{g}$ dry weight $\left(\mu \mathrm{mol} \mathrm{g}{ }^{-1} \mathrm{DW}\right)$. Different letters in each plot represent statistically significant differences at $p<0.05$.

\subsection{Chlorophyll a Fluorescence Parameters}

We investigated the effect of FA and SA treatments on photosynthetic parameters of salt-stressed Chinese cabbage plants by measuring fast chlorophyll $a$ fluorescence kinetics. Figure 2 shows the total photosynthetic performance index $\left(\mathrm{PI}_{\text {total }}\right)$ (see description of parameters in Table 1) in FA and SA-treated plants (10-100 $\mu \mathrm{M})$ under saline conditions $(150 \mathrm{mM} \mathrm{NaCl})$ compared to untreated plants grown under control conditions. $\mathrm{PI}_{\text {total }}$ is the most sensitive and the most informative photosynthetic parameter, which indicates the overall functional activity of both photosystems (PSII and PSI) and the intersystem electron transport chain [18-20]. 
a

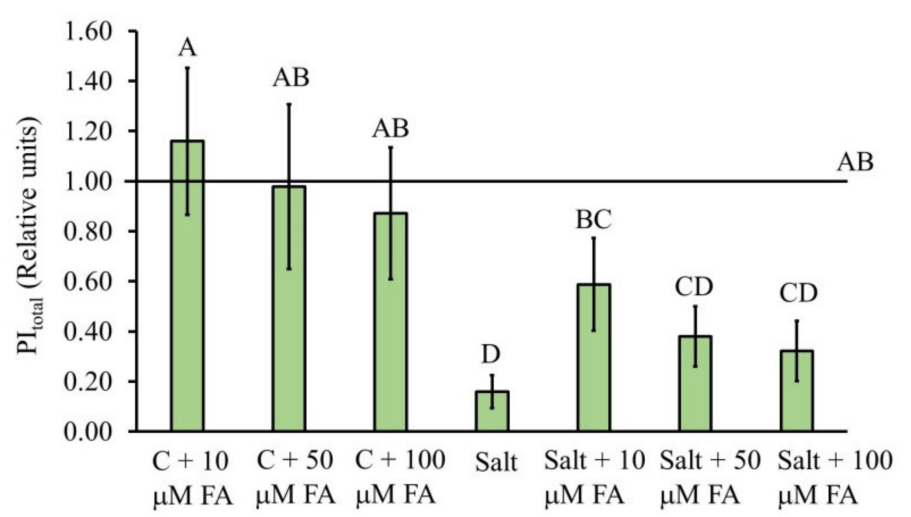

b

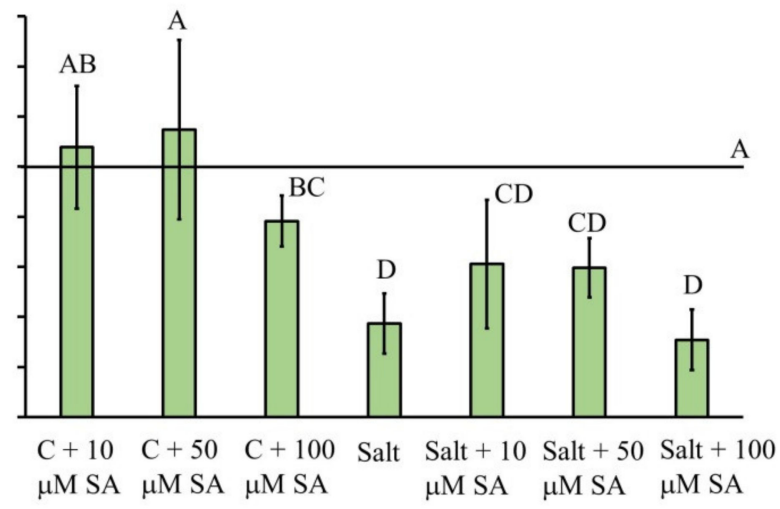

Figure 2. Effect of foliar treatments of $B$. rapa plants with ferulic acid (FA) (a) and salicylic acid (SA) (b) in concentrations of 10,50 , and $100 \mu \mathrm{M}$ on the overall photosynthetic performance index $\left(\mathrm{PI}_{\text {total }}\right)$ due to salt treatment $(150 \mathrm{mM})$ for $72 \mathrm{~h}$. All values are normalized to untreated control plants $(C)$, presented with the line at value 1 . Data are mean $\pm s d(n=6)$. Different letters in each plot represent statistically significant differences at $p<0.05$.

Table 1. Formulas and definitions of JIP test parameters $[19,20]$.

\begin{tabular}{|c|c|}
\hline Recorded Parameters & Description \\
\hline $\mathrm{F}_{0}$ & Minimal fluorescence intensity (20 $\mu$ s) \\
\hline $\mathrm{F}_{\mathrm{m}}$ & Maximal fluorescence intensity \\
\hline $\mathrm{V}_{\mathrm{J}}=\left(\mathrm{F}_{\mathrm{J}}-\mathrm{F}_{0}\right) /\left(\mathrm{F}_{\mathrm{m}}-\mathrm{F}_{0}\right)$ & Relative variable fluorescence at $2 \mathrm{~ms}$ \\
\hline $\mathrm{V}_{\mathrm{I}}=\left(\mathrm{F}_{\mathrm{I}}-\mathrm{F}_{0}\right) /\left(\mathrm{F}_{\mathrm{m}}-\mathrm{F}_{0}\right)$ & Relative variable fluorescence at $30 \mathrm{~ms}$ \\
\hline $\mathrm{F}_{\mathrm{V}}=\mathrm{F}_{\mathrm{m}}-\mathrm{F}_{0}$ & Maximal variable fluorescence \\
\hline $\mathrm{M}_{0}=(\Delta \mathrm{V} / \Delta \mathrm{t})_{0}$ & Approximated initial slope of relative variable fluorescence $F_{v}$ \\
\hline$\varphi_{\mathrm{P} 0}=\mathrm{TR}_{0} / \mathrm{ABS}=\mathrm{TR}_{0} / \mathrm{ABS}$ & Maximum quantum yield of PSII \\
\hline$\psi_{\mathrm{E} 0}=\mathrm{ET}_{0} / \mathrm{TR}_{0}=1-\mathrm{V}_{\mathrm{J}}$ & Probability that trapped exciton moves an electron further than $\mathrm{Q}_{\mathrm{A}}{ }^{-}$ \\
\hline$\varphi_{\mathrm{E} 0}=\mathrm{ET}_{0} / \mathrm{ABS}=\left[1-\left(\mathrm{F}_{0} / \mathrm{F}_{\mathrm{m}}\right)\right]\left(1-\mathrm{V}_{\mathrm{J}}\right)$ & Quantum yield for electron transport \\
\hline$\delta_{\mathrm{R} 0}=\mathrm{RE}_{0}-\mathrm{ET}_{0}=\left(1-\mathrm{V}_{\mathrm{I}}\right) /\left(1-\mathrm{V}_{\mathrm{J}}\right)$ & $\begin{array}{l}\text { Probability with which an electron from the intersystem electron carriers } \\
\text { moves to reduce end electron acceptors at the PSI acceptor side }\end{array}$ \\
\hline$\varphi_{\mathrm{R} 0}=\mathrm{RE}_{0} / \mathrm{ABS}=\left[1-\left(\mathrm{F}_{0} / \mathrm{F}_{\mathrm{m}}\right)\right] \psi_{\mathrm{E} 0} \delta_{\mathrm{R} 0}$ & Quantum yield for reduction of end electron acceptors at the PSI acceptor side \\
\hline $\mathrm{RC} / \mathrm{CS}_{0}=(\mathrm{ABS} / \mathrm{CS}) /(\mathrm{ABS} / \mathrm{RC})$ & Density of active RC per excited cross section \\
\hline $\mathrm{ABS} / \mathrm{RC}=\mathrm{M}_{0}\left(1 / \mathrm{V}_{\mathrm{J}}\right)\left[1 / \varphi_{\mathrm{P} 0}\right]$ & Absorption flux per active RC \\
\hline $\mathrm{TR}_{0} / \mathrm{RC}=\mathrm{M}_{0}\left(1 / \mathrm{V}_{\mathrm{J}}\right)$ & Trapping flux per active RC \\
\hline $\mathrm{ET}_{0} / \mathrm{RC}=\mathrm{M}_{0}\left(1 / \mathrm{V}_{\mathrm{J}}\right)\left(1-\mathrm{V}_{\mathrm{J}}\right)$ & Electron transport flux per active RC \\
\hline $\mathrm{DI}_{0} / \mathrm{RC}=(\mathrm{ABS} / \mathrm{RC})-\left(\mathrm{TR}_{0} / \mathrm{RC}\right)$ & Dissipation flux per active RC \\
\hline $\mathrm{RE}_{0} / \mathrm{RC}=\mathrm{M}_{0}\left(1 / \mathrm{V}_{\mathrm{J}}\right) \psi_{\mathrm{E} 0} \delta_{\mathrm{R} 0}$ & Electron flux reducing end electron acceptors at the PSI acceptor side, per RC \\
\hline$\gamma \mathrm{RC}=\mathrm{Chl}_{\mathrm{RC}} / \mathrm{Chl}_{\text {total }}=\mathrm{RC} /(\mathrm{ABS}+\mathrm{RC})$ & Probability that a PSII Chl molecule functions as RC \\
\hline $\mathrm{PI}_{\mathrm{ABS}}=\left[\gamma_{\mathrm{RC}} /\left(1-\gamma_{\mathrm{RC}}\right)\right]\left[\varphi_{\mathrm{P} 0} /\left(1-\varphi_{\mathrm{P} 0}\right)\right]\left[\psi_{\mathrm{E} 0} /\left(1-\psi_{\mathrm{E} 0}\right)\right]$ & Performance index on absorption basis \\
\hline $\mathrm{PI}_{\text {total }}=\mathrm{PI}_{\mathrm{ABS}}\left[\varphi_{\mathrm{R} 0} /\left(1-\varphi_{\mathrm{R} 0}\right)\right]$ & $\begin{array}{l}\text { Performance index for energy conservation from exciton to the reduction of } \\
\text { PSI end acceptors }\end{array}$ \\
\hline
\end{tabular}

As can be seen, $\mathrm{PI}_{\text {total }}$ was not affected in the control plants treated with 10 and $50 \mu \mathrm{M}$ SA and FA, although a higher concentration $(100 \mu \mathrm{M})$ showed a tendency to reduce PI $\mathrm{I}_{\text {total }}$, especially at SA.

Salt stress significantly decreased $\mathrm{PI}_{\text {total }}$ (up to $80 \%$ ) in Chinese cabbage leaves. Treatments of salt-stressed plants with $10 \mu \mathrm{M}$ FA and SA showed a tendency to improve photosynthetic performance by 6- and 1.5-fold, respectively, with a statistically significant improvement, observed only in the treatment with $10 \mu \mathrm{M}$ FA compared to salt-stressed plants.

Since the screening of applied concentrations of phenolic acids selected the $10 \mu \mathrm{M}$ concentration as one with a positive effect on $\mathrm{PI}_{\text {total }}$, we further investigated the photosynthetic mechanisms in samples of foliar treated with this favorable concentration of SA and FA. All investigated parameters are described in Table 1. Spider plots (Figure 3) show normalized values of calculated biophysical parameters in salt-stressed plants and salt-stressed plants treated with phenolic acids relative to unstressed controls. 

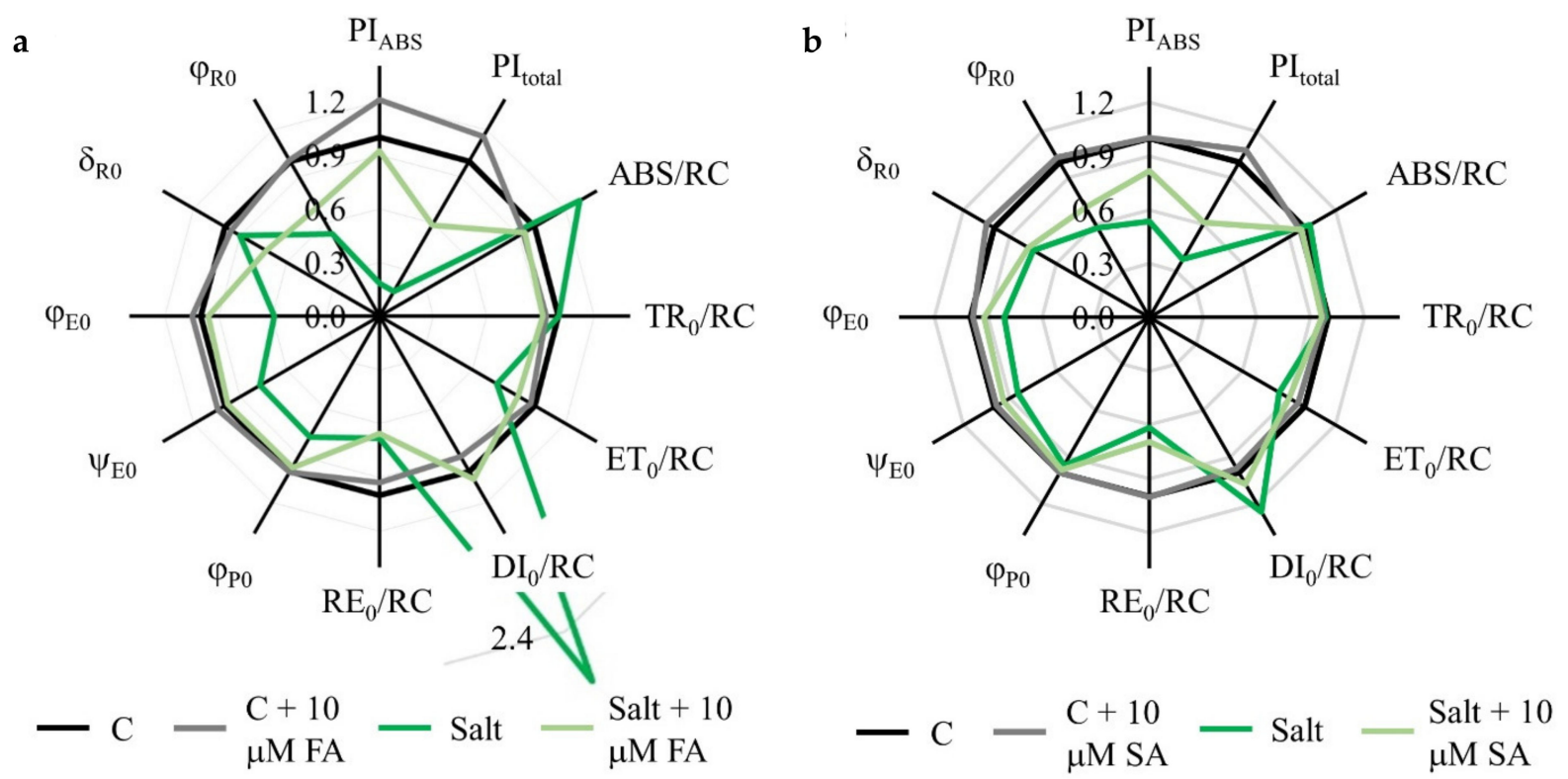

Figure 3. Effect of foliar treatments of B. rapa plants with ferulic acid (FA) (a) and salicylic acid (SA) (b) at concentrations of $10 \mu \mathrm{M}$ on the photosynthetic parameters due to salt treatment $(150 \mathrm{mM})$ for $72 \mathrm{~h}$. All values are expressed in relation to the untreated control (C), presented with the line at value 1. Abbreviations and descriptions of parameters are given in Table 1. Original data are shown in Table S1.

Although the experimental conditions were the same for the two sets of experiments and the trends in the parameters were the same, slight differences were observed in the salt-stressed plants.

Photosynthetic performance parameters $\mathrm{PI}_{\mathrm{ABS}}$, and consequently $\mathrm{PI}_{\text {total }}$, showed significant decreases in salt-stressed plants compared to the controls $\left(\mathrm{PI}_{\mathrm{ABS}}\right.$ is decreased in $19 \%$ while $\mathrm{PI}_{\text {total }}$ in $16 \%$ of the untreated controls). Photosynthetic performance indexes did not suffer such a significant decrease in salt-stressed plants treated with $10 \mu \mathrm{M}$ FA and $\mathrm{SA} ; \mathrm{PI}_{\mathrm{ABS}}$ and $\mathrm{PI}_{\text {total }}$ were $92 \%$ and $61 \%$ of the corresponding control values, respectively. Processes in reactive centers (RC) were differentially affected by salinity stress; while trapping flux per active $\mathrm{RC}\left(\mathrm{TR}_{0} / \mathrm{RC}\right)$ and electron transport flux per active $\mathrm{RC}\left(\mathrm{ET}_{0} / \mathrm{RC}\right)$ were not affected drastically, absorption flux per active RC (ABS/RC) and dissipation flux per active $R C\left(D_{0} / R C\right)$ were significantly increased upon salinity stress. Mitigating effects of $\mathrm{SA}$ and FA treatments were obvious, and maintained $\mathrm{ABS} / \mathrm{RC}$ and $\mathrm{DI}_{0} / \mathrm{RC}$ values on the levels of untreated controls. Moreover, electron flux reducing end electron acceptors at the PSI acceptor side, per $\mathrm{RC}\left(\mathrm{RE}_{0} / \mathrm{RC}\right)$ was significantly decreased in salt-stressed plants (about $40 \%$ ), and phenolic acid treatments did not show a positive effect on this parameter. The maximum quantum yield of PSII $\left(\varphi_{\mathrm{P} 0}\right)$ was about $22 \%$ lower in salt-stressed plants compared to the control but may be protected with FA and SA treatments. The quantum yield for reduction of end electron acceptors at the PSI $\left(\varphi_{\mathrm{R} 0}\right)$ was up to $40 \%$ lower in salt-treated plants compared to corresponding controls and may be significantly protected by phenolic acid treatments. The quantum yield for electron transport $\left(\varphi_{\mathrm{E} 0}\right)$ was also decreased by salt up to $40 \%$, and the negative effect of salt on this parameter may be alleviated by phenolic acids treatments. These data implicate that PSI is more sensitive to salinity stress than PSII. The influence of salt stress on PSI is even more clearly presented in O-P normalized curves (Figure 4). The O-P curves indicated differences in PSII and PSI functionality between control and salt-stressed plants, as well as salt-stressed plants treated with $10 \mu \mathrm{M}$ FA and SA. They demonstrated that the fluorescence intensity at defined transient steps was successively increased in salt stress conditions compared to the untreated controls, while FA and SA treatments of salt-stressed plants maintained the fluorescent intensities at the level of controls. This finding confirms a protective role of applied phenolic acids for photosynthetic apparatus. 

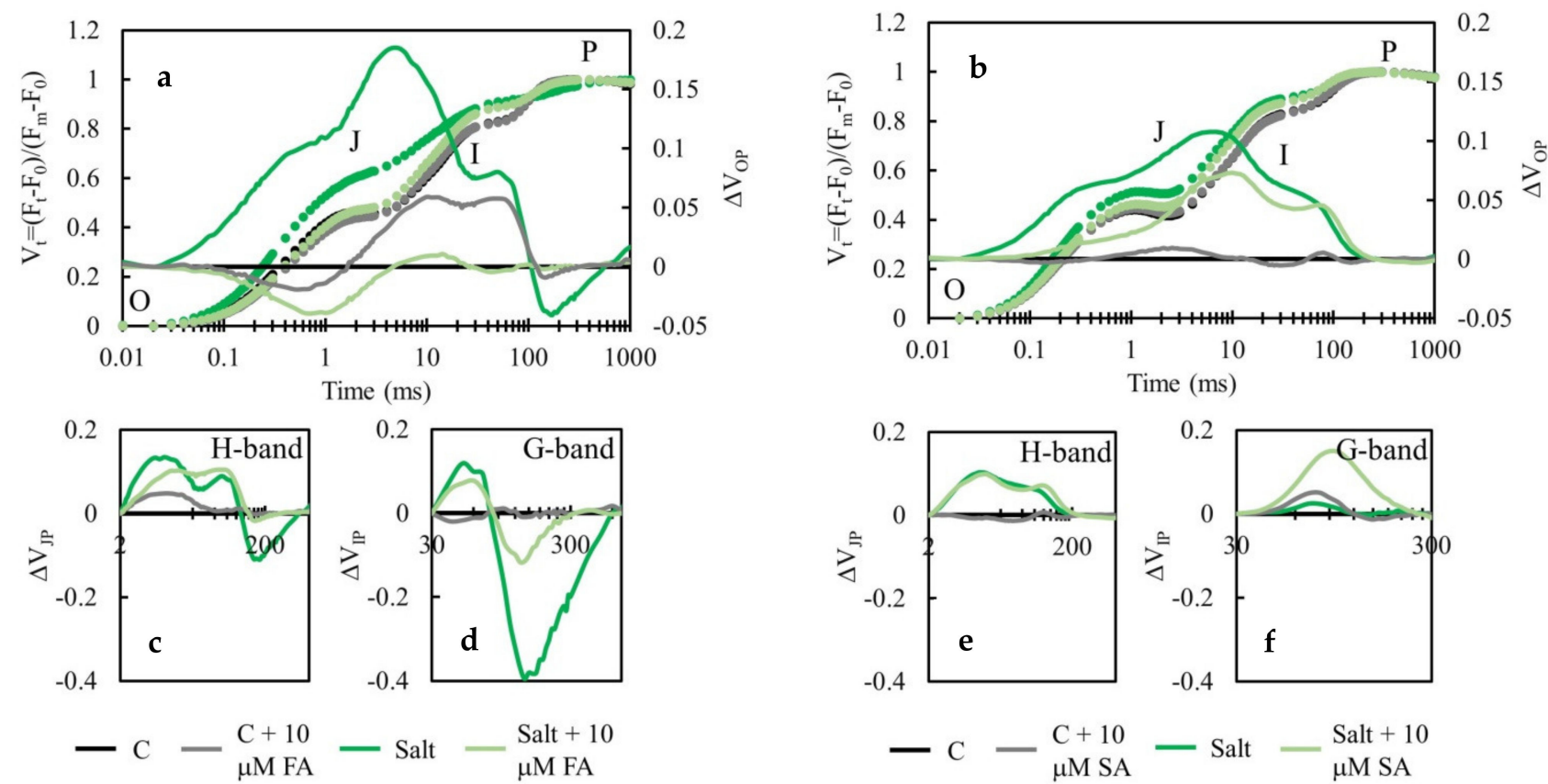

Figure 4. Effect of foliar treatments with ferulic acid (FA; $(\mathbf{a}, \mathbf{c}, \mathbf{d}))$ and salicylic acid $(\mathrm{SA} ;(\mathbf{b}, \mathbf{e}, \mathbf{f}))$ at a concentration of $10 \mu \mathrm{M}$ on the chlorophyll a fluorescence transient curves due to salt treatment $(150 \mathrm{mM})$ for $72 \mathrm{~h}$ compared to the untreated control (C). Kinetics data were normalized between O-P (a,b), J-P (H-band; (c,e)), and I-P (G-band; (d,f)) steps and plotted as difference kinetics $\Delta \mathrm{Vt}$ in corresponding time ranges. Each curve represents the average kinetics of six replicates per treatment. Typical O-J-I-P steps are marked in the relative variable fluorescence transient, $\Delta \mathrm{Vt}(\mathbf{a}, \mathbf{b})$.

H- and G- bands were the highest for salt-treated plants, while treatment with FA showed a protective role against salinity on the photosynthetic apparatus and decreased specific bands.

\subsection{Phenolic Compounds and Antioxidative Activities}

Phenolic compounds are a diverse group of specialized metabolites generally involved in plant protection against abiotic stresses [9]. Table 2 shows the results of polyphenolic groups' contents and antioxidant activities in an experimental setup with FA treatment, while Table 3 presents data in an experimental setup with SA treatment. Under our experimental conditions, the untreated controls of $B$. rapa plants contained total phenols of 28-33 mg of gallic acid per $\mathrm{g}$ of dry weight (GAE g $\left.{ }^{-1} \mathrm{DW}\right)$, total phenolic acids of 5-7 mg of caffeic acid per $\mathrm{g}$ of dry weight $\left(\mathrm{CAE}^{-1} \mathrm{DW}\right)$, total flavonoids of 6-8 $\mathrm{mg}$ of catechin per $\mathrm{g}$ of dry weight (CE g $\left.{ }^{-1} \mathrm{DW}\right)$, and total flavanols of 58-66 $\mu \mathrm{g} \mathrm{CE} \mathrm{g}^{-1} \mathrm{DW}$ (Tables 2 and 3). Antioxidant activities evaluated by ferric reducing/antioxidant power assay (FRAP assay) and 2,2-Diphenyl-1-picrylhydrazyl assay (DPPH assay) were 32-42 $\mu \mathrm{mol}$ Trolox per $\mathrm{g}$ of dry weight (TE $\mathrm{g}^{-1} \mathrm{DW}$ ) and $41-57 \mu \mathrm{mol} \mathrm{Fe}^{2+} \mathrm{g}^{-1} \mathrm{DW}$, respectively (Tables 2 and 3). Salt stress significantly decreased the content of all groups of phenolic compounds by $20-35 \%$, as well as antioxidant activity compared to the untreated control (Tables 2 and 3). 
Table 2. Content of groups of polyphenolic compounds and antioxidant activities in the methanol extracts of Chinese cabbage leaves subjected to salt stress $(150 \mathrm{mM} \mathrm{NaCl})$ and different concentrations of ferulic acid $(0,10,50$, and $100 \mu \mathrm{M})$ compared to the untreated control. The results are mean $\pm S D(n=3)$, light gray represents the lowest values, while bright green represents the highest values. Different letters represent statistically significant differences for each individual specialized metabolite compared to treatments $(p<0.05)$. Abbreviations: $\mathrm{S}$, salt (150 mM NaCl); C, control, FA, ferulic acid; GAE, equivalents of gallic acid; CAE, equivalents of caffeic acid; CE, equivalents of catechin; FRAP, ferric reducing/antioxidant power assay; DPPH, 2,2-Diphenyl-1-picrylhydrazyl assay; TE, Trolox equivalents; DW, dry weight.

\begin{tabular}{|c|c|c|c|c|c|c|}
\hline \multirow{3}{*}{ Treatment } & \multicolumn{4}{|c|}{ Groups of Specialized Metabolites } & \multicolumn{2}{|c|}{ Antioxidant Activity } \\
\hline & $\begin{array}{c}\text { Total } \\
\text { Polyphenols }\end{array}$ & $\begin{array}{c}\text { Total Phenolic } \\
\text { Acids }\end{array}$ & Total Flavonoids & Total Flavanols & DPPH Assay & FRAP Assay \\
\hline & $\begin{array}{c}\text { mg GAE g-1 } \\
\text { DW (\%) }\end{array}$ & $\underset{(\%)}{\operatorname{mg~CAE~g}} \mathrm{g}^{-1} \mathrm{DW}$ & $\underset{(\%)}{\operatorname{mg~CE~g-1~DW~}}$ & $\underset{(\%)}{\mu g \mathrm{CE} \mathrm{g}^{-1} \mathrm{DW}}$ & $\underset{(\%)}{\mu m o l ~ T E ~} g^{-1} \mathrm{DW}$ & $\begin{array}{c}\mu \mathrm{mol} \mathrm{Fe}^{2+} \mathrm{g}^{-1} \\
\mathrm{DW}(\%)\end{array}$ \\
\hline $\mathrm{C}$ & $\begin{array}{c}32.66 \pm 0.40 c \\
(100)\end{array}$ & $6.91 \pm 0.08$ a $(100)$ & $5.63 \pm 0.03$ a $(100)$ & $\begin{array}{c}66.46 \pm 0.19 \mathrm{bc} \\
(100)\end{array}$ & $\begin{array}{c}41.76 \pm 0.60 \mathrm{~b} \\
(100)\end{array}$ & $\begin{array}{c}41.07 \pm 0.10 \mathrm{~b} \\
(100)\end{array}$ \\
\hline $\mathrm{C}+10 \mu \mathrm{M} F A$ & $\begin{array}{c}35.03 \pm 0.20 \mathrm{a} \\
(107.26)\end{array}$ & $\begin{array}{l}6.01 \pm 0.02 \mathrm{~b} \\
(86.98)\end{array}$ & $\begin{array}{l}5.69 \pm 0.04 \mathrm{a} \\
\quad(101.07)\end{array}$ & $\begin{array}{c}75.57 \pm 0.79 \mathrm{a} \\
(113.71)\end{array}$ & $\begin{array}{l}40.23 \pm 0.17 \mathrm{c} \\
(96.34)\end{array}$ & $\begin{array}{c}44.73 \pm 0.54 \mathrm{a} \\
(108.91)\end{array}$ \\
\hline $\mathrm{C}+50 \mu \mathrm{M} F A$ & $\begin{array}{c}25.52 \pm 0.04 \mathrm{~d} \\
(78.14)\end{array}$ & $\begin{array}{c}4.10 \pm 0.04 \mathrm{~g} \\
\quad(59.33)\end{array}$ & $\begin{array}{l}4.12 \pm 0.01 \mathrm{~d} \\
\quad(73.18)\end{array}$ & $\begin{array}{l}65.38 \pm 0.55 c \\
(98.37)\end{array}$ & $\begin{array}{l}34.66 \pm 0.23 \mathrm{f} \\
(83.00)\end{array}$ & $\begin{array}{c}32.42 \pm 0.21 \mathrm{e} \\
(78.94)\end{array}$ \\
\hline $\mathrm{C}+100 \mu \mathrm{M} F A$ & $\begin{array}{c}32.45 \pm 0.11 \mathrm{c} \\
(99.36)\end{array}$ & $\begin{array}{l}5.36 \pm 0.03 c \\
(77.57)\end{array}$ & $\begin{array}{l}5.24 \pm 0.04 b \\
(93.07)\end{array}$ & $\begin{array}{c}58.27 \pm 0.93 \mathrm{~d} \\
(87.68)\end{array}$ & $\begin{array}{c}37.00 \pm 0.23 \mathrm{e} \\
(88.60)\end{array}$ & $\begin{array}{c}37.02 \pm 0.56 \mathrm{~d} \\
(90.14)\end{array}$ \\
\hline$S$ & $\begin{array}{c}23.57 \pm 0.04 \mathrm{e} \\
(72.17)\end{array}$ & $\begin{array}{l}4.32 \pm 0.01 \mathrm{f} \\
\quad(62.52)\end{array}$ & $\begin{array}{l}3.81 \pm 0.01 \mathrm{f} \\
(67.67)\end{array}$ & $\begin{array}{l}51.02 \pm 0.67 \mathrm{f} \\
\quad(76.77)\end{array}$ & $\begin{array}{c}38.98 \pm 0.06 \mathrm{~d} \\
(93.34)\end{array}$ & $\begin{array}{c}25.99 \pm 0.18 \mathrm{fg} \\
(63.28)\end{array}$ \\
\hline $\mathrm{S}+10 \mu \mathrm{M}$ FA & $\begin{array}{c}34.22 \pm 0.12 b \\
(104.78)\end{array}$ & $\begin{array}{l}5.25 \pm 0.03 c \\
\quad(75.98)\end{array}$ & $\begin{array}{l}4.85 \pm 0.01 \mathrm{c} \\
(86.15)\end{array}$ & $\begin{array}{l}67.97 \pm 0.93 \mathrm{~b} \\
(102.27)\end{array}$ & $\begin{array}{c}51.39 \pm 0.23 \mathrm{a} \\
(123.06)\end{array}$ & $\begin{array}{c}39.74 \pm 0.46 c \\
(96.76)\end{array}$ \\
\hline $\mathrm{S}+50 \mu \mathrm{M}$ FA & $\begin{array}{c}23.60 \pm 0.18 \mathrm{e} \\
(72.26)\end{array}$ & $\begin{array}{l}4.84 \pm 0.04 \mathrm{~d} \\
\quad(70.04)\end{array}$ & $\begin{array}{c}3.71 \pm 0.03 \mathrm{~g} \\
(65.90)\end{array}$ & $\begin{array}{c}44.04 \pm 0.57 \mathrm{~g} \\
(66.27)\end{array}$ & $\begin{array}{c}39.85 \pm 0.13 \mathrm{~cd} \\
(95.43)\end{array}$ & $\begin{array}{c}25.27 \pm 0.29 \mathrm{~g} \\
(61.53)\end{array}$ \\
\hline $\mathrm{S}+100 \mu \mathrm{M} F A$ & $\begin{array}{c}24.07 \pm 0.13 \mathrm{e} \\
(73.70)\end{array}$ & $\begin{array}{c}4.52 \pm 0.03 \mathrm{e} \\
(65.41)\end{array}$ & $\begin{array}{c}3.97 \pm 0.03 \mathrm{e} \\
(70.52)\end{array}$ & $\begin{array}{c}53.08 \pm 0.54 \mathrm{e} \\
(79.87)\end{array}$ & $\begin{array}{c}37.75 \pm 0.50 \mathrm{e} \\
(90.40)\end{array}$ & $\begin{array}{c}26.76 \pm 0.07 \mathrm{f} \\
(65.16)\end{array}$ \\
\hline
\end{tabular}

Table 3. Content of groups of polyphenolic compounds and antioxidant activities in the methanol extracts of Chinese cabbage leaves subjected to salt stress $(150 \mathrm{mM} \mathrm{NaCl})$ and different concentrations of salicylic acid $(0,10,50$, and $100 \mu \mathrm{M})$ compared to the untreated control. The results are mean $\pm \mathrm{SD}(\mathrm{n}=3)$, light gray represents the lowest values, while bright green represents the highest values. Different letters represent statistically significant differences for each individual specialized metabolite compared to each treatment $(p<0.05)$. Abbreviations: $\mathrm{S}$, salt (150 mM NaCl); C, control, SA, salicylic acid; GAE, equivalents of gallic acid; CAE, equivalents of caffeic acid; CE, equivalents of catechin; FRAP, ferric reducing/antioxidant power assay; DPPH, 2,2-Diphenyl-1-picrylhydrazyl assay; TE, Trolox equivalents; DW, dry weight.

\begin{tabular}{|c|c|c|c|c|c|c|}
\hline \multirow{3}{*}{ Treatment } & \multicolumn{4}{|c|}{ Groups of Specialized Metabolites } & \multicolumn{2}{|c|}{ Antioxidant Activity } \\
\hline & $\begin{array}{c}\text { Total } \\
\text { Polyphenols }\end{array}$ & $\begin{array}{c}\text { Total Phenolic } \\
\text { Acids }\end{array}$ & Total Flavonoids & Total Flavanols & DPPH Assay & FRAP Assay \\
\hline & $\underset{(\%)}{\operatorname{mg~GAE~g-1~DW~}}$ & $\underset{(\%)}{\operatorname{mg} C A E g^{-1} \mathrm{DW}}$ & $\underset{(\%)}{\operatorname{mg~CE~} \mathrm{g}^{-1} \mathrm{DW}}$ & $\mu \mathrm{g} \mathrm{CE} \mathrm{g}_{(\%)}^{-1} \mathrm{DW}$ & $\underset{(\%)}{\mu \mathrm{mol}} \mathrm{TE}^{-1} \mathrm{DW}$ & $\begin{array}{c}\mu \mathrm{mol} \mathrm{Fe} \mathrm{Fe}^{2+} \mathrm{g}^{-1} \\
\mathrm{DW}(\%)\end{array}$ \\
\hline $\mathrm{C}$ & $\begin{array}{c}27.48 \pm 0.17 b \\
(100)\end{array}$ & $\begin{array}{l}4.89 \pm 0.02 \mathrm{~d} \\
(100)\end{array}$ & $7.88 \pm 0.04$ c (100) & $\begin{array}{c}58.47 \pm 0.58 b \\
(100)\end{array}$ & $\begin{array}{c}31.92 \pm 0.47 b \\
(100)\end{array}$ & $\begin{array}{c}56.98 \pm 0.15 c \\
(100)\end{array}$ \\
\hline $\mathrm{C}+10 \mu \mathrm{M}$ SA & $\begin{array}{c}29.79 \pm 0.21 \mathrm{a} \\
(108.40)\end{array}$ & $\begin{array}{l}5.81 \pm 0.06 \mathrm{c} \\
\quad(118.81)\end{array}$ & $\begin{array}{l}8.84 \pm 0.09 \mathrm{~b} \\
\quad(112.18)\end{array}$ & $\begin{array}{c}69.07 \pm 0.86 \mathrm{a} \\
(118.13)\end{array}$ & $\begin{array}{c}31.56 \pm 0.35 b \\
(98.87)\end{array}$ & $\begin{array}{c}58.40 \pm 0.61 \mathrm{~b} \\
(102.49)\end{array}$ \\
\hline $\mathrm{C}+50 \mu \mathrm{M} \mathrm{SA}$ & $\begin{array}{l}25.78 \pm 0.25 c \\
\quad(93.81)\end{array}$ & $\begin{array}{l}6.16 \pm 0.06 \mathrm{~b} \\
\quad(125.97)\end{array}$ & $\begin{array}{l}8.94 \pm 0.12 b \\
\quad(113.45)\end{array}$ & $\begin{array}{c}58.88 \pm 1.11 b \\
(100.7)\end{array}$ & $\begin{array}{l}28.63 \pm 0.58 \mathrm{c} \\
(89.69)\end{array}$ & $\begin{array}{c}57.13 \pm 0.20 c \\
(100.26)\end{array}$ \\
\hline $\mathrm{C}+100 \mu \mathrm{M}$ SA & $\begin{array}{c}30.10 \pm 0.24 \mathrm{a} \\
(109.53)\end{array}$ & $\begin{array}{l}6.47 \pm 0.05 a \\
\quad(132.31)\end{array}$ & $\begin{array}{l}9.59 \pm 0.04 \mathrm{a} \\
(121.70)\end{array}$ & $\begin{array}{c}43.30 \pm 1.14 \mathrm{~d} \\
(74.06)\end{array}$ & $\begin{array}{l}35.31 \pm 0.57 \mathrm{a} \\
(110.62)\end{array}$ & $\begin{array}{c}62.29 \pm 0.28 \mathrm{a} \\
(109.32)\end{array}$ \\
\hline S & $\begin{array}{l}22.43 \pm 0.15 \mathrm{e} \\
(81.62)\end{array}$ & $\begin{array}{c}3.99 \pm 0.07 \mathrm{~g} \\
(81.60)\end{array}$ & $\begin{array}{l}5.74 \pm 0.06 \mathrm{~g} \\
\quad(72.84)\end{array}$ & $\begin{array}{c}31.69 \pm 0.59 \mathrm{f} \\
(54.20)\end{array}$ & $\begin{array}{c}23.21 \pm 0.44 \mathrm{e} \\
(72.71)\end{array}$ & $\begin{array}{c}32.84 \pm 0.02 \mathrm{~g} \\
(57.63)\end{array}$ \\
\hline $\mathrm{S}+10 \mu \mathrm{M}$ SA & $\begin{array}{l}21.64 \pm 0.22 \mathrm{f} \\
\quad(78.75)\end{array}$ & $\begin{array}{l}4.23 \pm 0.03 \mathrm{f} \\
(86.50)\end{array}$ & $\begin{array}{c}7.16 \pm 0.07 \mathrm{~d} \\
(90.86)\end{array}$ & $\begin{array}{c}34.91 \pm 0.77 \mathrm{e} \\
(59.71)\end{array}$ & $\begin{array}{c}23.55 \pm 0.34 \mathrm{de} \\
(73.78)\end{array}$ & $\begin{array}{c}35.73 \pm 0.40 \mathrm{f} \\
(62.70)\end{array}$ \\
\hline $\mathrm{S}+50 \mu \mathrm{MSA}$ & $\begin{array}{c}24.79 \pm 0.26 \mathrm{~d} \\
(90.21)\end{array}$ & $\begin{array}{c}3.80 \pm 0.01 \mathrm{~h} \\
(77.71)\end{array}$ & $\begin{array}{c}6.10 \pm 0.03 \mathrm{f} \\
(77.41)\end{array}$ & $\begin{array}{c}46.93 \pm 0.30 c \\
(80.26)\end{array}$ & $\begin{array}{c}24.77 \pm 0.41 \mathrm{~d} \\
(77.60)\end{array}$ & $\begin{array}{c}42.86 \pm 0.09 \mathrm{e} \\
(75.22)\end{array}$ \\
\hline $\mathrm{S}+100 \mu \mathrm{M}$ SA & $\begin{array}{c}22.70 \pm 0.35 \mathrm{e} \\
(82.61)\end{array}$ & $\begin{array}{c}4.54 \pm 0.05 \mathrm{e} \\
(92.84)\end{array}$ & $\begin{array}{c}6.66 \pm 0.13 \mathrm{e} \\
(84.52) \\
\end{array}$ & $\begin{array}{c}42.16 \pm 0.66 \mathrm{~d} \\
(72.11)\end{array}$ & $\begin{array}{c}21.58 \pm 0.49 \mathrm{f} \\
(67.61)\end{array}$ & $\begin{array}{c}44.43 \pm 0.18 \mathrm{~d} \\
(77.97)\end{array}$ \\
\hline
\end{tabular}

Treatments of unstressed and salt-stressed plants with FA (Table 2) and SA (Table 3) resulted in changes in phenolic compound content and antioxidant activities. Treatment of controls with FA at a concentration of $10 \mu \mathrm{M}$ significantly increased total phenolics and 
total flavanols, as well as antioxidant activity, as determined by FRAP (by $7 \%, 13 \%$, and $8 \%$, respectively, compared with controls) (Table 2). Higher concentrations of FA showed an inhibitory effect on the accumulation of polyphenols (except flavanols) in unstressed plants. FA treatments showed some positive effects on salt-stressed plants. FA at a concentration of $10 \mu \mathrm{M}$ significantly increased all groups of phenolic compounds (13-32\%) during salt stress compared to untreated salt-stressed plants. The antioxidant capacity of plants treated with $10 \mu \mathrm{M}$ FA was also significantly increased (approximately 30\% compared to saltstressed plants). SA showed a more positive effect and increased the accumulation of most specialized metabolites and antioxidant activity at all applied concentrations (10, 50, and $100 \mu \mathrm{M}$ ) in unstressed plants (Table 3). Thus, $100 \mu \mathrm{M} \mathrm{SA}$ increased total phenolics, phenolic acids, flavonoids, and antioxidant activity, as measured by DPPH and FRAP, by $9 \%, 32 \%, 21 \%, 10 \%$, and $9 \%$, respectively, compared with controls, whereas flavanols were decreased by $18 \%$ compared with controls. SA was less effective than FA under salt stress conditions and caused an improvement in polyphenol accumulation by about $10-26 \%$ at concentrations of 50 and $100 \mu \mathrm{M}$. Antioxidant activity was improved by up to $20 \%$ in salt-stressed plants by SA treatments $(100 \mu \mathrm{M})$.

Since cabbage plants are known to be rich in the phenolic acids FA, SiA, and SA [17], and the flavonoids, subclass flavonols, kaemferol and quercetin [21], we analyzed these metabolites in detail by LC-MS/MS in B. rapa leaves after salt stress and treatments with $\mathrm{FA}$ and SA at a $10 \mu \mathrm{M}$ concentration. Individual metabolites were identified based on retention time (RT) and specific multiple reaction monitoring (MRM) transitions (Table S2, Figures S1 and S2).

Changes in the content of selected metabolites caused by salinity stress and at FA and SA foliar treatments are shown in Figure 5. As can be seen, the content of FA and SiA were up to 4.1 and $3.5 \mathrm{mg} \mathrm{g}^{-1} \mathrm{DW}$, respectively, in the untreated controls, while the concentrations of SA, KAE, and QUE were up to $10.8,3.8$, and $1.7 \mu \mathrm{g} \mathrm{g}^{-1} \mathrm{DW}$.

a
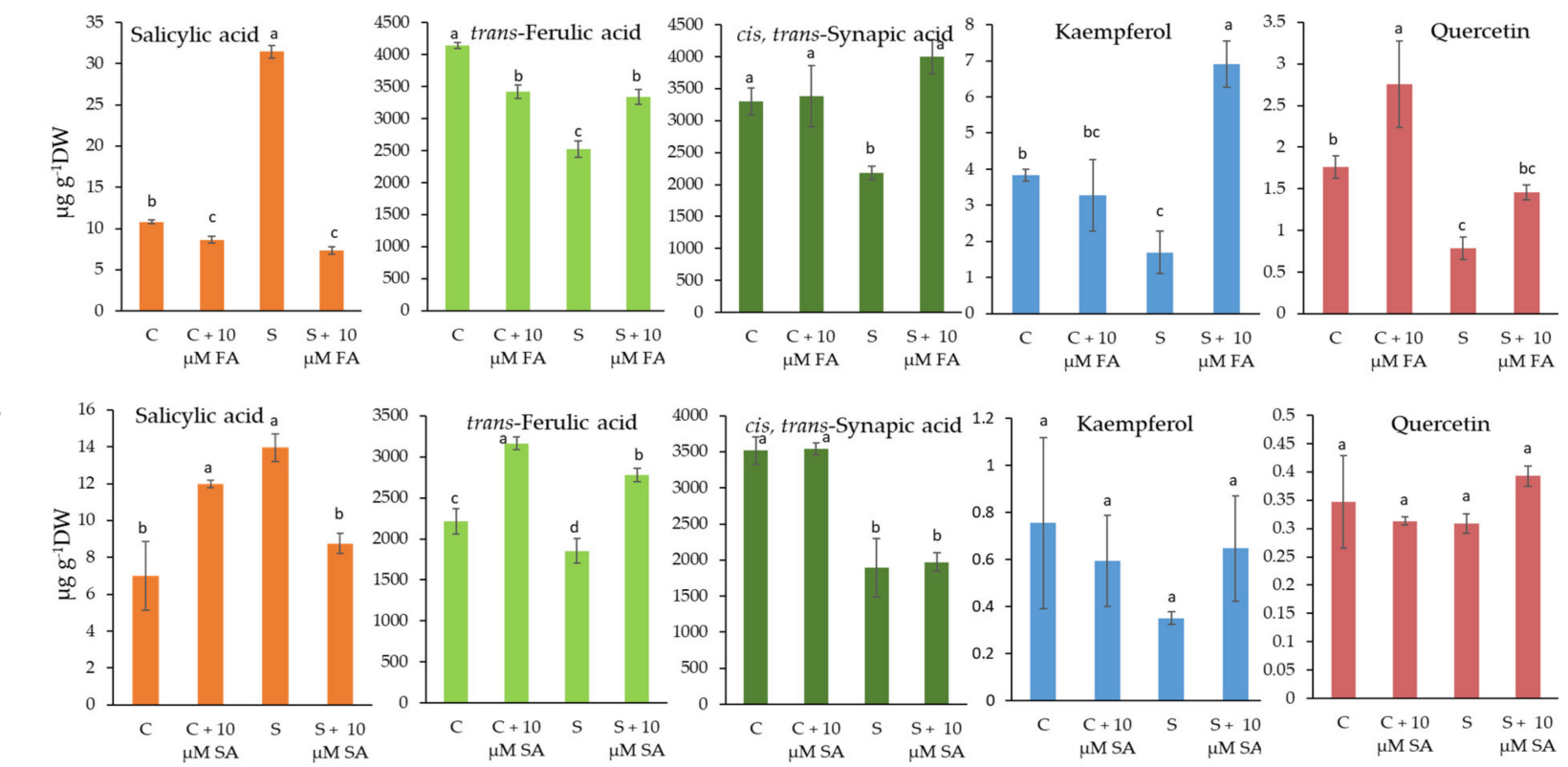

Figure 5. Effect of foliar treatments of B. rapa with ferulic acid (FA) (a), and salicylic acid (SA) (b)) at a concentration of $10 \mu \mathrm{M}$ on the selected phenolic compounds (Salicylic acid (SA), trans-Ferulic acid (trans-FA, cis, trans-Synapic acid (SiA), Kaempferol (KAE), and Quercetin (QUE)) measured by LC-MS/MS due to salt treatment (S, $150 \mathrm{mM} \mathrm{NaCl)} \mathrm{for}$ $72 \mathrm{~h}$. Data are mean $\pm \mathrm{sd}(\mathrm{n}=3)$. Different letters represent statistically significant differences for each individual specialized metabolite $(p<0.05)$.

Salinity stress caused a reduction in all metabolites studied except SA compared to the untreated control. Briefly, the phenolic acids trans-FA and SiA were reduced by up to $39 \%$ 
and $46 \%$, respectively. The flavonols KAE and QUE were both reduced by salt stress by up to $56 \%$. On the other hand, SA was significantly increased by salt stress (up to 2.9-fold compared to the untreated control).

Foliar treatments with FA and SA had a positive effect on stressed plants and caused a significant decrease in SA (2.2- and 1.6-fold, respectively), while other metabolites increased compared to salt-stressed plants. Thus, SA leaf treatment increased trans-FA, KAE, and QUE (1.5-, 1.9-, and 1.3-fold, respectively), while it did not affect SiA content. Moreover, FA foliar treatment increased the content of trans-FA, SiA, KAE and QUE (1.3-, 1.8-, 4.1-, and 1.9-fold, respectively) significantly, compared to salt-stressed plants.

To evaluate oxidative stress upon salt stress and phenolic acid treatments, we measured lipid peroxidation and expressed the content of malonaldehyde (MDA). As can be seen in Figure 6, lipid peroxidation levels were increased significantly in salt stress compared to the corresponding controls. Phenolic acid (SA and FA) treatments in salt stress showed the tendency to lower lipid peroxidation; thus, the MDA level was lower in salt-stressed plants treated with phenolic acids compared to salt-stressed plants.

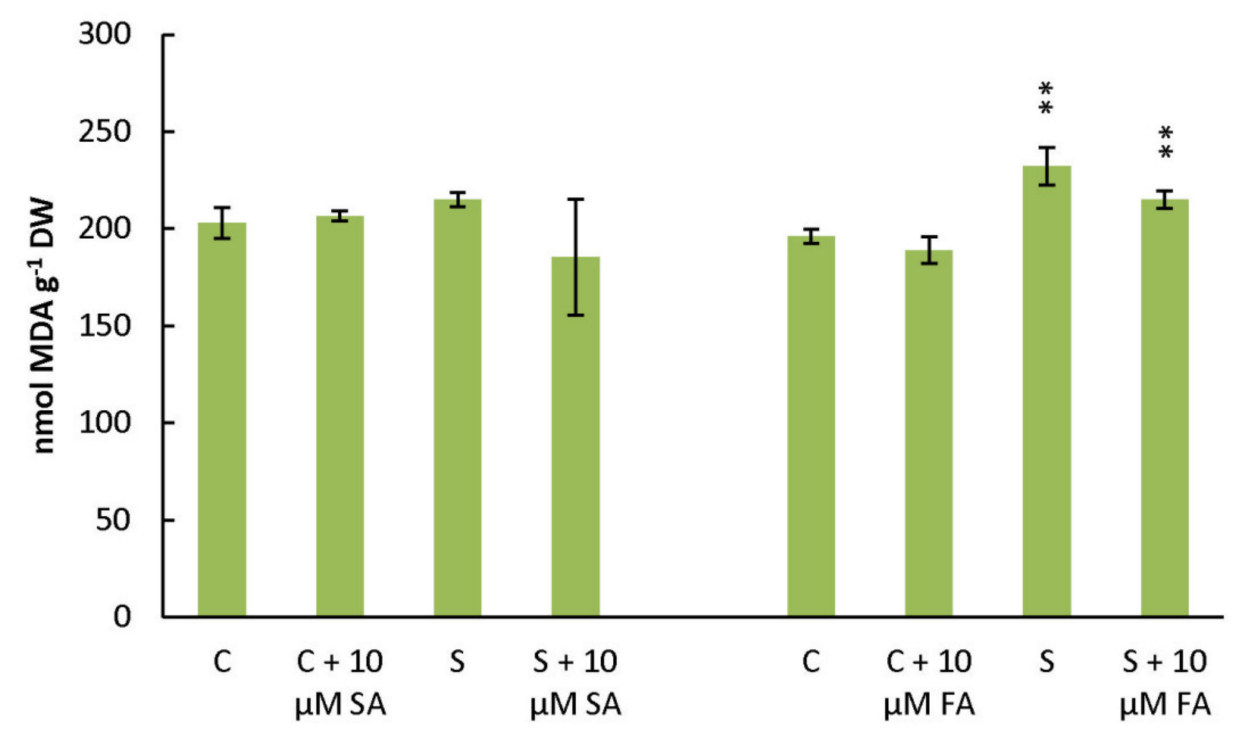

Figure 6. Effect of foliar treatments of B. rapa with phenolic acids (SA and FA, at a concentration of $10 \mu \mathrm{M}$ ) on the lipid peroxidation measured by the malonaldehyde (MDA) method due to salt treatment (150 mM NaCl) for $72 \mathrm{~h}$. S, salt treatment; C, control; SA, salicylic acid; FA, ferulic acid. Asterisks indicate a significant difference in the measured parameters in controls compared to treatments in a Student's $t$-test (** correspond to $p$-values of $0.001<p<0.01$ ).

\section{Discussion}

Many species and varieties of Brassica crops, including Chinese cabbage, are germinated and raised to the seedling stage under favorable growing conditions (greenhouse or growth chamber), and then transplanted to the field under environmental conditions. In this early stage, transplanted plantlets are often exposed to unpleasant conditions and may suffer from increased soil salinity. Foliar treatment of salt-sensitive plants with compounds that are at least partly responsible for tolerance in salt-tolerant species is one of the strategies to mitigate the negative effects of increased soil salinity on the plants. Based on our previous studies, FA and SA might be part of the salt response mechanisms in salt-tolerant Brassica species (kale) compared to salt-sensitive ones (Chinese cabbage) [17]. Therefore, we investigated here whether foliar application of Chinese cabbage with FA and SA can reduce the effects of short-term salt stress and harden the plants during this sensitive growth period. One-month-old plantlets were subjected to short-term salt stress $(150 \mathrm{mM} \mathrm{NaCl}$, for $72 \mathrm{~h}$ ) and treated with FA and SA at a concentration of 10-100 $\mu \mathrm{M}$. In our previous publication, we reported short-term salinity responses of three Brassicas, 
including Chinese cabbage, on the physiological and biochemical levels [7]. Based on our published data $[7,17]$, we decided to evaluate the effects of phenolic acid treatments by measuring only selected markers, such as proline, chlorophyll $a$ fluorescence parameters, major groups of phenolic compounds (total polyphenols, total phenolic acids, total flavonoids, total flavanols), antioxidant activity, and selected phenolic compounds (FA, SiA, SA, KAE, QUE), which are known to be major antioxidants in Brassicaceae $[17,21,22]$.

\subsection{Attenuating Effects of FA and SA on Short-Term Salinity Stressed Plants: Stress Markers}

Proline has been confirmed as a reliable stress marker under elevated salinity conditions, suggesting a positive correlation between proline accumulation and plant stress [23,24]. The proline level was 18-23 fold increased after $72 \mathrm{~h}$ of salt-stress in Chinese cabbage leaves (Figure 1) compared to the unstressed controls that are in agreement with our previously published data [7]. Proline can act as an osmoprotectant, but it is also known as a metal chelator, an antioxidant defense molecule, and a signaling molecule [24]. Phenolic acids treatments at a concentration of $10 \mu \mathrm{M}$ decreased the level of proline in salt-stressed plants, suggesting that $10 \mu \mathrm{M}$ foliar treatments with FA and SA diminish the stress intensity caused by salt in Chinese cabbage plants. This is in agreement with previous research that confirms a positive correlation of the content of proline and the stress intensity in Brassicas [7,25], showing that proline content was increasing in a dose-dependent manner with the intensity of salinity stress in different Brassica crops. The application of higher concentrations of FA (50 and $100 \mu \mathrm{M}$ ) in combination with salinity stress resulted in increased proline content compared to salt-stressed untreated plants. This may suggest that higher concentrations of applied FA in combination with increased salinity caused additional stress for Chinese cabbage plants. It may be due to the pro-oxidant activity of FA at higher concentrations, as already reported [26]. The correlation of proline content, applied FA, and stress response depends on plant species, type of stress, and stress duration. Thus, it was shown that pretreatment with FA increased proline content in cucumber leaves [27] and in blueberries (Vaccinium corymbosum L.) [28] and participated in protection from desiccation stress and heat stress, respectively. The application of higher concentrations of SA (50 and $100 \mu \mathrm{M})$, in combination with salinity stress, caused a decrease of proline content compared to salt-stressed untreated plants, although they are not as effective as the lowest applied concentration $(10 \mu \mathrm{M})$.

The correlation between proline accumulation and stress tolerance is controversial, and it is still a matter of debate. In some plant species, high proline accumulation is linked to increased stress tolerance, while in others, it is a sign of stress sensitivity [23,24]. Different correlations between proline and stress are also reported in Brassicaceae. Comparative research between Chinese cabbage, white cabbage, and kale under salinity [7] and drought [29] stress suggest that higher proline content is linked to more sensitive species/varieties. Furthermore, comparative evaluation of different varieties of kale (Brassica oleracea var. acephala) under osmotic stress showed a higher accumulation of proline in more sensitive varieties (unpublished data). However, Mohamed et al. [30] showed that proline in rapeseed cultivars subjected to salt stress correlated positively with salt tolerance. Hayat et al. [25] also showed a positive correlation between proline accumulation and salt tolerance in a comparative study of different $B$. juncea varieties. Thus, proline accumulation and its correlation with salinity and osmotic stress tolerance seem to be species or even variety-specific in Brassicaceae.

Another stress marker is salicylic acid (SA), which was significantly increased by salt stress (up to 2.9-fold compared to the untreated control) (Figure 5). It is not surprising, since SA acts as a stress hormone and increased levels of SA have already been documented in a number of plants, including Brassicaceae, under stress conditions [7,12]. As described by Khan et al. [31], salicylic acid can regulate various plant metabolic processes and modulate the production of osmolytes and specific metabolites. The exogenous application of SA, and especially FA, lowered the level of endogenous SA, as well as proline level, as markers of stress status under our experimental conditions. 


\subsection{FA and SA Treatments Stabilize Photosynthetic Parameters under Salinity Stress}

Photosynthesis has been shown to be negatively affected by salt stress in Brassica species depending on natural salt tolerance $[7,25,30,32]$. The total photosynthetic performance index $\left(\mathrm{PI}_{\text {total }}\right)$ is the most sensitive and the most informative photosynthetic parameter, which indicates the overall functional activity of both photosystems (PSII and PSI) and the intersystem electron transport chain [18-20]. Short-term salt stress significantly decreased $\mathrm{PI}_{\text {total }}$ (up to $80 \%$ ) in Chinese cabbage leaves compared to the unstressed controls. Moreover, parameters, such as $\mathrm{RE}_{0} / \mathrm{RC}, \varphi_{\mathrm{R} 0}$ and $\varphi_{\mathrm{E} 0}$, were up to $40 \%$ lower in salt-treated plants compared to corresponding controls, while $\varphi_{\mathrm{P} 0}$ was about $22 \%$ lower in salt-stressed plants compared to the unstressed control. Similarly, Dabrowski et al. [20] reported that the diminution of PSII activity and impairment of PSI function significantly decreased the total performance index in ryegrass. Oukarroum et al. [33] detected salt-induced inhibition of both PSII and PSI electron transport activities in duckweed.

$\mathrm{PI}_{\text {total }}$ was not affected in control plants treated with 10 and $50 \mu \mathrm{M} \mathrm{SA}$ and FA, although a higher concentration $(100 \mu \mathrm{M})$ showed a tendency to reduce $\mathrm{PI}_{\text {total }}$, especially for SA (Figure 2). This is in agreement with published data reporting that higher SA concentrations $(1.0 \mathrm{mM})$ have an inhibitory effect on photosynthesis and overall growth performance in B. juncea cultivars [34]. Moreover, a high concentration of FA (1.5 mM) inhibited photosynthesis and can be used as a bioherbicide [35].

Under the short-term salt stress, the same concentration of FA and SA $(10 \mu \mathrm{M})$ that lower the proline and SA level in salt-treated plants toward control level showed a positive effect on photosynthetic parameters measured by chlorophyll $a$ fluorescence (Figure 3). Treatments of salt-stressed plants with $10 \mu \mathrm{M}$ FA and SA showed a tendency to improve $\mathrm{PI}_{\text {total }}$ by 6- and 1.5-fold, respectively. Furthermore, the negative effect of salt on the maximum quantum yield of PSII $\left(\varphi_{\mathrm{P} 0}\right)$, quantum yield for reduction of end electron acceptors at the PSI $\left(\varphi_{R 0}\right)$, and quantum yield for electron transport $\left(\varphi_{\mathrm{E} 0}\right)$ were alleviated by phenolic acid treatments. The O-P curves demonstrated that the fluorescence intensity at defined transient steps was successively increased in salt stress conditions compared to the untreated controls, while FA and SA treatments of salt-stressed plants maintained the fluorescent intensities at the level of controls (Figure 4). This finding confirms a protective role of applied phenolic acids for photosynthetic apparatuses. Furthermore, FA treatment showed a protective role against salinity on the photosynthetic apparatus and lower specific $\mathrm{H}-$ and G-bands due to the possible generation of cyclic electron flow around PSI [36]. However, SA treatment revealed an almost identical amplitude of the H-band in both salttreated plants, while the G-band in salt-stressed plants showed drastically lower amplitude compared to the SA treated ones. In some cases, a smaller amplitude could be the result of a stronger limitation on $\mathrm{PQH}_{2}$ reoxidation due to the slowdown of electrons from PSII (lower $\varphi_{\mathrm{E} 0}$ and $\psi_{\mathrm{E} 0}$ ) [37].

The protective role of SA to photosynthetic apparatuses has been reported earlier for a number of species [12]. In salt-treated tomato plants, the effective quantum yield ( $\phi P S I I)$ and the photochemical quenching coefficient $(\mathrm{qP})$, which declined significantly under salt stress, were partially restored in SA hardened plants. Similarly, the net $\mathrm{CO}_{2}$ fixation rate was higher in SA-treated tomato than in the salt-treated control [38]. Salinity also reduced photosynthetic efficiency by inhibiting chlorophyll synthesis, nitrate reductase activity, chlorophyll fluorescence, stomatal conductance, net photosynthetic, and transpiration rates in Ethiopian mustard (Brassica carinata), and SA application alleviated the adverse effects of salinity and improved the performance of the photosynthetic parameters [39].

To our knowledge, the effect of FA on the photosynthetic apparatus has not been studied to date. In a recent publication, it was shown that a high concentration of FA (1.5 mM) inhibits photosynthesis and can be used as a bioherbicide [35], although there are no reports on the effects of lower concentrations of FA on the photosynthetic apparatus. However, it has been shown that plants with higher levels of endogenous FA showed better photosynthetic performance under stress conditions [40]. Up-regulations of 4-hydroxycinnamic acid and ferulic acid were consistent with photosynthetic performance in the early stages 
of drought in rice, suggesting that 4-hydroxycinnamic acid and ferulic acid are considered key metabolites for drought tolerance in rice [41]. Brassica cultivars with a higher content of FA [17] showed better photosynthetic performance under salinity stress [7]. These data suggest a positive correlation between FA and photosynthetic performance depending on concentration, which is confirmed by our results.

\subsection{FA and SA Treatments Increase an Accumulation of Phenolic Antioxidants and Antioxidant Activity under Stress Conditions}

Metabolic disorder in salt-stressed plants was notable in polyphenolic content and consequently in antioxidant activity. As can be seen in Tables 2 and 3, salt stress significantly decreased the content of all groups of phenolic compounds by $20-35 \%$, as well as antioxidant activity compared to the untreated control. Furthermore, salinity stress caused a reduction in the selected metabolites studied; trans-FA and SiA were reduced by up to $39 \%$ and $46 \%$, respectively, the flavonoids KAE and QUE were both reduced by salt stress by up to $56 \%$. Only endogenous SA that acts as a stress hormone and presents one of the stress markers was increased up to 2.9-fold, as we have already discussed above.

It is evident that the treatments of SA and especially FA increased the content of potent phenolic antioxidants (phenolic acids and flavonoids) under stress conditions in the leaves of $B$. rapa, which is consistent with the increased antioxidant activities compared with salt-stressed untreated plants (Tables 2 and 3). This is in agreement with the level of lipid peroxidation (Figure 6). Salinity stress caused an increase of lipid peroxidation (MDA content) compared to the corresponding controls, while phenolic acid treatments showed the tendency of decreasing the MDA content. In our experimental design, FA appears to be a stronger stimulator of polyphenols accumulation and antioxidant activity than SA. The treatment of salt-stressed plants with $10 \mu \mathrm{M}$ FA accumulated total polyphenols, total flavanols, and antioxidant activity on the level above that measured in the untreated and unstressed control. This may be explained by the fact that hydroxycinnamic acids (FA), compared with the corresponding hydroxybenzoic acids (SA), exhibit higher antioxidant activity, which has been attributed to the greater hydrogen-donating and radical-stabilizing ability of the $\mathrm{CH}=\mathrm{CH}-\mathrm{COOH}$ group [9].

Higher levels of phenolic compounds and antioxidant activities under stress conditions, after treatments with FA and SA, correlate positively with the improvement of the photosynthetic parameters, the decrease of stress markers (proline and salicylic acid), and decrease of lipid peroxidation level in B. rapa plants. The phenylpropanoid biosynthetic pathway has been shown to be activated under abiotic stress conditions in some plants, leading to the accumulation of several phenolic compounds that are widely recognized as protective biomolecules [10]. A positive correlation between increasing salt tolerance and increasing levels of phenolic compounds has been observed in many halophytes (salttolerant species) [42]. In addition, salt tolerance has also been reported to correlate with levels of specialized metabolites, including phenolic compounds, in different plant species and cultivars [9]. Transgenic tobacco plants (AroG plants) that had significantly higher levels of phenolic metabolites showed improved tolerance to salt stress [43]. Soil salinity increased the concentrations of leaf phenolics, including chlorogenic acid, in honeysuckle as a mechanism of acclimation to salt stress [44]. Martinez et al. [45] reported that cinnamic acid, $p$-coumaric acid, and p-coumaryl CoA, in addition to flavonols, were several times higher in tomato due to salinity, heat, and combined stress (heat + salinity) compared to control plants. Furthermore, endogenous ferulic acid and $p$-coumaric acid are thought to be involved in the response mechanism to salt stress in rice [46]. Low salinity also increased phenolic compounds at a certain level in various Brassica species [47,48].

The exogenous application of phenolic compounds to improve salinity response has been reported mainly through SA as phenolic acid but also as a plant stress hormone [12]. However, the effect of SA depends on the concentration of the applied SA, the plant species, and the developmental stage of the plants. In general, low concentrations of applied SA can improve abiotic stress tolerance, while high concentrations induce oxidative stress, resulting in increased sensitivity to abiotic stress [12]. As described by Khan et al. [31], 
salicylic acid can regulate various plant metabolic processes, modulate the production of osmolytes and specific metabolites, which is consistent with our results.

Less information is available for FA effects on phenolic compounds and antioxidant activity, as well as stress tolerance. It was shown that in addition to SA, increased salinity tolerance of wheat seedlings was also obtained after treatment with sinapic, caffeic, ferulic, and $p$-coumaric acids [13]. The authors reported that the exogenous application of phenolic acids reduced electrolyte leakage in NaCl-stressed seedlings, decreased $\mathrm{H}_{2} \mathrm{O}_{2}$ and malondialdehyde levels, and activated antioxidant enzymes. Pretreatment with FA protected cucumbers from desiccation stress by reducing lipid peroxidation due to the activation of antioxidant enzymes and by increasing proline and soluble sugar content in leaves [27]. Pretreatment with FA alleviated heat stress in blueberries (Vaccinium corymbosum) by increasing the endogenous FA content, which is consistent with our results, and decreasing the accumulation of reactive oxygen species, as well as increasing the proline and soluble sugar content [28].

In addition to phenolic acids, flavonoids are also potent antioxidants capable of inhibiting the formation of ROS and also quenching ROS once formed [9,49]. There are not many reports on the direct involvement of quercetin or kaempferol in salinity stress response. The treatment of tomato with quercetin under salinity resulted in the alleviation of ionic, osmotic, and oxidative stress [50]. Kaempferol, quercetin-3-rutenoside (rutin), and dihydrokaempferol have been reported to accumulate as a stress response under heat and the combination of salt and heat stress, along with increased levels of gene transcripts in the phenylpropanoid pathway, are responsible for their synthesis [45]. Quercetin and kaempferol have been reported to mediate prolonged abiotic stress in peanut (Arachis hypogaea) [51].

Treatments with SA and methyl-salicylate (MeSA) were reported to enhance the activity of phenylalanine ammonia-lyase (PAL, a key enzyme in the phenylpropanoid biosynthesis pathway) and upregulate the expression of genes of the phenylpropanoid pathway (such as PAL, C4H, 4CL, CHS, CHI, F3H, DFR, ANS, and UFGT) [31,52]. Under our experimental conditions, the accumulation of FA, KAE, and QUE in salt-stressed plants upon SA treatment suggest that genes involved in their biosynthesis were upregulated by exogenously added SA. There is a lack of information on the FA mode of action upon foliar treatments. Since FA, SiA, KAE, and QUE were increased in salt-stressed plants upon FA treatment; we may speculate that the applied FA stimulated gene expressions of the phenylpropanoid pathway. It is interesting that the non-stressed control showed a lower level of FA upon treatment compared to untreated controls. It may be due to the inhibition of endogenous FA biosynthesis by exogenously applied FA. The mode of action of foliar-applied FA on salt-stressed plants is still unknown and needs to be investigated in the future.

\subsection{Conclusions}

Based on our results, we may conclude that foliar treatments of salt-stressed plants with SA and FA (especially $10 \mu \mathrm{M}$ concentration) showed a positive effect on salt-stressed plants by attenuating the stress effects. In short, phenolic acid treatments decreased proline and endogenous SA content compared to untreated salt-stressed plants. In addition, the content of phenolic compounds was increased. In particular, an increase in endogenous phenolic acids FA and SiA and flavonoids QUE and KAE was observed. Consequently, antioxidant activity was increased in stressed plants by the SA and FA treatments. In addition, photosynthetic performance was improved. Photosynthetic parameters, such as $\mathrm{PI}_{\mathrm{ABS}}$, $\mathrm{PI}_{\text {total }}, \varphi_{\mathrm{P} 0}, \varphi_{\mathrm{E} 0}, \psi_{\mathrm{E} 0}, \varphi_{\mathrm{R} 0}$, and $\mathrm{DI}_{0} / \mathrm{RC}$, which were significantly disturbed under salt stress, were protected by phenolic acid treatments. FA resulted in a better ameliorative effect on salt stress compared to SA, probably due to a better antioxidant capacity. Treatments of plants with FA and SA can be used to help plants cope with salinity stress, at least during the sensitive period of adaptation of the plantlets after transplantation to the field. However, the mechanisms of action of phenolic compounds in salt stress response and their effects in prolonged salt stress are still unclear and require further investigation. 


\section{Materials and Methods}

\subsection{Plant Material and Experimental Conditions}

Seeds of Chinese cabbage (Brassica rapa L. ssp. pekinensis (Lour.) Hanelt cv. Cantonner Witkrop) were obtained from ISP, International Seed Processing GmbH, Quedlinburg, Germany. Plants were hydroponically cultivated as previously described [7] at $21^{\circ} \mathrm{C}$, with $16 / 8 \mathrm{~h}$ light $\left(115 \mu \mathrm{mol} \mathrm{m} \mathrm{m}^{-2} \mathrm{~s}^{-1}\right) /$ dark cycles. After 4 weeks of cultivation, plant sets were foliar treated (by spraying) with phenolic acids: salicylic acid (SA) and trans-ferulic acid (FA) in the concentration range of 10,50 , and $100 \mu \mathrm{M}$, and a set sprayed with distilled water. The dose of SA and FA was approximately $0.5 \mathrm{~mL}$ per plant per treatment. Half of these pretreated plants were subjected to salt stress, and the $\mathrm{NaCl}$ concentration in the hydroponic solution was gradually increased up to $150 \mathrm{mM} \mathrm{NaCl}$. The treatments were started $24 \mathrm{~h}$ before salt application and continued for the next 3 days (once daily at the same time). Plants of the same developmental stage that were not exposed to $\mathrm{NaCl}$ stress served as controls (C). We examined 8 sets of plants (each set contained 8 plants in a single pot) for each phenolic acid treatment: control ( $\mathrm{C}$ and foliar spray with water, no $\mathrm{NaCl}$ treatment), $\mathrm{C}+10 \mu \mathrm{M}$ FA (SA), C + $50 \mu \mathrm{M}$ FA (SA), C + $100 \mu \mathrm{M}$ FA (SA), salt (150 mM NaCl and foliar spray with water), salt $+10 \mu \mathrm{M}$ FA (SA), salt $+50 \mu \mathrm{M}$ FA (SA), and salt + $100 \mu \mathrm{M}$ FA (SA).

The photosynthetic parameters were measured $72 \mathrm{~h}$ after salt application in vivo, and plants were harvested, frozen in liquid nitrogen, and stored at $-80^{\circ} \mathrm{C}$. The plant material was lyophilized and used for the analysis of stress markers and specialized metabolites.

\subsection{Fast Chlorophyll a Fluorescence Kinetics}

The photosynthetic measurements were performed in vivo with six individual plants per treatment and appropriate controls. Photosynthetic efficiency was determined by chlorophyll $a$ fluorescence measurements using a Plant Efficiency Analyzer (PEA, Hansatech, King's Lynn, Norfolk, UK). The plants were dark-adapted for approximately $30 \mathrm{~min}$ before measurements. Chlorophyll fluorescence transients (OJIP) were induced by applying a pulse of saturating red light with a maximum intensity of $650 \mathrm{~nm}$ and a photon flux of $3200 \mu \mathrm{mol} \mathrm{m} \mathrm{m}^{-2} \mathrm{~s}^{-1}$. Fluorescence changes were measured over $1 \mathrm{~s}$, and the data obtained were analyzed using the JIP-test that represents the translation of the original data into biophysical parameters [53]. To evaluate the state of the photosynthetic apparatus of measured plants, selected structural and functional parameters calculated from the JIP test were selected. The calculations and descriptions of the OJIP test parameters used are shown in Table S1. OJIP transients are presented as mean values of six measurements for each plant group. To compare recorded OJIP transients for specific events in the OP, JP, and IP phases, the difference in relative variable fluorescence was calculated and presented as the differences $\Delta \mathrm{VOP}, \Delta \mathrm{VJP}$, and $\Delta \mathrm{VIP}$ normalized to the control $[18,20]$.

\subsection{Proline Analysis}

Proline concentrations were determined as described previously for Brassica plants [17]. The extraction was performed with $30 \mathrm{mg}$ of the lyophilized tissue in $70 \%$ ethanol, and proline concentration was measured at $530 \mathrm{~nm}$ with a UV/VIS spectrophotometer (BioSpec$1601 \mathrm{E}$, Shimadzu, Kyoto, Japan) using a reaction mixture (1\% ninhydrin in 60\% acetic acid and $20 \%$ ethanol). The results are calculated as $\mu \mathrm{mol} L$-proline per g dry weight $\left(\mu \mathrm{mol} \mathrm{g}^{-1} \mathrm{dw}\right)$.

\subsection{Determination of Phenolic Compounds and Antioxidant Activity}

For the measurement of polyphenolic compounds (total phenolics (TP), total phenolic acids (TPA), total flavonoids (TF), and total flavanols (TFL)) and antioxidant activities (FRAP and DPPH assays), $30 \mathrm{mg}$ of freeze-dried tissue were extracted in $1 \mathrm{~mL} 80 \%$ methanol using a Mixer Mill MM 400 (Retsch, Haan, Germany) for 5 min at $30 \mathrm{~Hz}$, after which the extracts were incubated in a sonicator $(10 \mathrm{~min})$ and further mixed in a tube rotator $(1 \mathrm{~h}, 15 \mathrm{rpm})$. The extracts were then centrifuged (Eppendorf centrifuge, $10 \mathrm{~min}, 13,000 \mathrm{rpm}$ ), and the supernatants were used for all of the analyses described below. 
TP were analyzed using the Folin-Ciocalteu method according to Singleton and Rossi [54], and the results were presented as equivalents of gallic acid per dry weight (mg GAE $\mathrm{g}^{-1} \mathrm{dw}$ ). TPA were determined using Arnow's reagent according to the European Pharmacopoeia [55]; TPA data were expressed as equivalents of caffeic acid per dry weight $\left(\mathrm{mg} \mathrm{CAE} \mathrm{g}{ }^{-1} \mathrm{dw}\right)$. TF were measured using the $\mathrm{AlCl}_{3}$ method [56], and results were presented as equivalents of catechin per dry weight $\left(\mathrm{mg} \mathrm{CE} \mathrm{g}^{-1} \mathrm{dw}\right)$. TFL were analyzed by the p-dimethylaminocinnamaldehyde (DMACA) method [57], and the results were presented as equivalents of catechin per dry weight $\left(\mathrm{mg} \mathrm{CE} \mathrm{g}^{-1} \mathrm{dw}\right)$. Antioxidant activity of methanol plant extracts was evaluated by ferric reducing/antioxidant power assay (FRAP) and DPPH radical scavenging capacity assay. The FRAP was measured as described earlier [58]. The results were expressed as $\mu \mathrm{mol} \mathrm{Fe} \mathrm{F}^{2+} \mathrm{g}^{-1} \mathrm{dw}$. The DPPH method was measured according to Brand-Williams et al. [59], and the results were expressed as $\mu \mathrm{mol}$ Trolox equivalents per gram dry weight ( $\left.\mu \mathrm{mol} \mathrm{TE} \mathrm{g}^{-1} \mathrm{dw}\right)$.

\subsection{Extraction and LC-MS/MS Analysis of Selected Phenolic Compounds}

Samples for the analysis of endogenous selected phenolic compounds (salicylic acid, ferulic acid, sinapic acid, kaempferol, and quercetin) were prepared as follows: lyophilized plant material $(30 \mathrm{mg}$ ) was extracted in $80 \% \mathrm{MeOH}$ with the addition of the antracene9-carboxilic acid (ANT) as an internal standard at a final concentration of $20 \mu \mathrm{g} \mathrm{mL}^{-1}$. Supernatants were evaporated in a vacuum concentrator (Sarvant SPD1010 Intergrated SpeedVac System, Thermo Fisher Scientific, Göteborg - Sweden at $40{ }^{\circ} \mathrm{C}$. Pellets were subjected to hot alkaline hydrolysis as described earlier [60]. After adjustment of the $\mathrm{pH}$ of samples to $2-3$, ethyl acetate was added $(3 \times 500 \mu \mathrm{L})$, the organic phase containing phenolic compounds was collected, and the solvents were evaporated. Dry residues were stored at $-20{ }^{\circ} \mathrm{C}$ prior to analysis.

HPLC-grade standard sinapic acid (SiA), trans-ferulic acid ( $t$-FA), quercetine (QUE), and salicylic acid (SA) were purchased from Sigma Aldrich (Saint Louis, MO, USA), kaempferol (KAE) from Carl Roth (Karlsruhe, Germany), and the internal standard antracene9-carboxilic acid (ANT) from Alfa Aesar (Haverhill, MA, USA). MiliQ ${ }^{\circledR}$ water $\left(18.2 \mathrm{M} \Omega \mathrm{cm}^{-1}\right.$; purified by MiliQ water purification system (Millipore, Bedford, MA, USA)) and HPLC gradient-grade methanol (MeOH) (J.T.Baker, Center Valley, USA) were used with analyticalgrade formic acid (Acros Organics, Geel, Belgium) for mobile phase preparation.

The analyte stock solutions $\left(1 \mathrm{mg} \mathrm{mL}^{-1}\right)$ in methanol were used for the preparation of calibration curves. Five calibration points were constructed in $50 \% \mathrm{MeOH}+0.1 \%$ formic acid (mobile phase) with the addition of antracene-9-carboxilic acid at a final concentration of $20 \mu \mathrm{g} \mathrm{mL}^{-1}$. Analyte concentrations were: $30-300 \mu \mathrm{g} \mathrm{mL}^{-1}$ for SiA; $6-60 \mu \mathrm{g} \mathrm{mL} \mathrm{mL}^{-1}$ for trans-FA, $0.3-1.25 \mu \mathrm{g} \mathrm{mL}^{-1}$ for SA; and 0.02-0.2 $\mu \mathrm{g} \mathrm{mL}^{-1}$ for KAE and QUE, respectively. Samples were dissolved in $400 \mu \mathrm{L}$ of the mobile phase prior to analysis and together with calibrants injected into the LC column at a volume of $20 \mu \mathrm{L}$. The calibration curve was obtained by linear regression; the peak area ratio was plotted versus the analyte concentration. A quality control (QC) sample containing $100 \mathrm{ng} \mathrm{mL} \mathrm{m}^{-1}$ of each analyte and instrumental blank were injected after every few runs. During analysis, all instrumental blank samples were negative, and the area of each analyte in QC samples was repeatable. LC-MS/MS analysis was carried out using an Agilent Technologies 1200 series HPLC system equipped with a binary pump, a vacuum membrane degasser, an automated autosampler, and an injector interfaced with 6420 triple quadrupole mass spectrometer with electrospray ionization source (ESI) (Agilent Technologies Inc., Palo Alto, CA, USA). The separation was performed on a Zorbax XDP C18 column $(75 \times 4.6 \mathrm{~mm}, 3.5 \mu \mathrm{m}$ particle size) (Agilent Technologies Inc., Palo Alto, CA, USA). Solvents for the analysis were $0.1 \%$ formic acid in water (solvent $A$ ) and methanol (solvent $B$ ).

The gradient was applied as follows: $0 \mathrm{~min} 60 \% \mathrm{~A}, 3-12 \mathrm{~min} 60 \% \mathrm{~A}-30 \% \mathrm{~A}, 5-20 \mathrm{~min}$ $30 \%$ A-0\% A, 20-25 min 0\% A, 25.1-30 min 60\% A. The flow rate was $0.3 \mathrm{~mL} \mathrm{~min}^{-1}$.

The electrospray ionization source was operated in negative mode, and the samples were detected in the multiple reaction monitoring (MRM) mode with a dwell time of $10 \mathrm{~ms}$ 
per MRM transition. The desolvation gas temperature was $350{ }^{\circ} \mathrm{C}$ with a flow rate of $6.0 \mathrm{~L} \mathrm{~min}^{-1}$. The capillary voltage was $3.5 \mathrm{kV}$. The collision gas was nitrogen. Fragmentor voltages were $100 \mathrm{~V}$ for SiA, $135 \mathrm{~V}$ for KAE and QUE, and $70 \mathrm{~V}$ for trans-FA, ANT, and SA. The collision energy was set at $15 \mathrm{~V}$ for QUE and SA, at $20 \mathrm{~V}$ for KAE, at $10 \mathrm{~V}$ for SiA and trans-FA, and for ANT it was set at $5 \mathrm{~V}$.

All data acquisition and processing were performed using Agilent MassHunter software.

\subsection{Lipid Peroxidation Measurement}

Lipid peroxidation was determined by the malonaldehyde (MDA) method according to Heath and Packer [61] with a slight modification. Approximately $30 \mathrm{mg}$ of lyophilized plant leaf tissue was homogenized by Mixer Mill Retsch MM 400 for 3.5 min at $30 \mathrm{~Hz}$. To the homogenized powder, $1 \mathrm{~mL}$ of $0.1 \%$ TCA was added, and the suspension was centrifuged at $13,000 \mathrm{rpm}$ at $4{ }^{\circ} \mathrm{C}$ for $10 \mathrm{~min}$. The reaction mixture of either $400 \mu \mathrm{L}$ of the obtained supernatant (or $400 \mu \mathrm{L}$ of $0.1 \%$ TCA) and MDA reagent ( $0.5 \%$ thiobarbituric acid (TBA) in $20 \%$ TCA, Sigma) was incubated at $95^{\circ} \mathrm{C}$ for $25 \mathrm{~min}$ and centrifuged at $13,000 \mathrm{rpm}$ and $4{ }^{\circ} \mathrm{C}$ for $10 \mathrm{~min}$. The absorbance of supernatants was measured at 532 and $600 \mathrm{~nm}$, and the content of MDA was calculated using an extinction coefficient of $155 \mathrm{mM}^{-1} \mathrm{~cm}^{-1}$. MDA content was expressed as nmol MDA g ${ }^{-1} \mathrm{DW}$.

\subsection{Statistical Analysis}

The data were analyzed with the STATISTICA program (Version Stat Soft. Statistica.v 10.0. Enterprise). ANOVA was used to analyze the relevant factors, and values were considered to be significant at $p<0.05$. Tukey's HSD post-hoc test was used for multiple comparisons. Data presented in the text, figures, and tables are means \pm standard deviation of three biological replicates $(n=3)$ for biochemical markers and phenolic compounds. One biological replicate consisted of 7-8 plants grown in the same pot. Fluorescence measurements were performed in vivo, and data are means \pm standard deviation of 6 biological replicates ( $n=6$, one plant is one biological replicate).

Supplementary Materials: The following are available online at https://www.mdpi.com/article/ 10.3390/plants10112346/s1, Figure S1: Representative MRM chromatograms of standard mixture (calibrant 1), Figure S2: Representative MRM chromatograms of sample B. rapa treated with $10 \mu \mathrm{M}$ ferulic acid under salinity stress ( $150 \mathrm{mM} \mathrm{NaCl})($ Salt $+10 \mu \mathrm{M} \mathrm{FA})$, Table S1: Original and normalized chlorophyll a fluorescence parameters measured after $72 \mathrm{~h}$ of foliar treatments with ferulic acid (FA) and salicylic acid (SA) at a concentration of $10 \mu \mathrm{M}$ due to salt treatment $(150 \mathrm{mM})$ compared to the control (C), Table S2: List of phenolic compounds and used internal standard (anthracene-9-carboxylic acid) determined by UPLC-MS/MS, and the MRM transitions of the precursor to product ion pairs.

Author Contributions: Conceptualization, B.S.-S.; methodology, I.L., S.M., L.B. and A.S.; validation, L.B. and I.P.; formal analysis, I.L., S.M., L.B. and A.S.; investigation, I.L., S.M., L.B., I.P. and B.S.-S.; resources, B.S.-S.; writing-original draft preparation, B.S.-S.; writing-review and editing, B.S.-S., I.L., S.M., L.B., A.S. and I.P.; visualization, I.L., S.M., L.B. and B.S.-S.; supervision, B.S.-S.; project administration, B.S.-S.; funding acquisition, B.S.-S. All authors have read and agreed to the published version of the manuscript.

Funding: This research was funded by the Croatian Science Foundation, grant number IP-2014-094359 and by the Operational Program Competitiveness and Cohesion 2014-2020 and the European regional fund under the specific Scheme "Scheme to strengthening applied research in proposing actions for climate change adaptation", grant number KK.05.1.1.02.0005.

Institutional Review Board Statement: Not applicable.

Informed Consent Statement: Not applicable.

Data Availability Statement: Not applicable.

Conflicts of Interest: The authors declare no conflict of interest. 


\section{References}

1. Moore, F.C.; Baldos, U.; Hertel, T.; Diaz, D. New science of climate change impacts on agriculture implies higher social cost of carbon. Nat. Commun. 2017, 8, 1607. [CrossRef] [PubMed]

2. Shah, A.N.; Tanveer, M.; Abbas, A.; Fahad, S.; Baloch, M.S.; Ahmad, M.I.; Saud, S.; Song, Y. Targeting salt stress coping mechanisms for stress tolerance in Brassica: A research perspective. Plant Physiol. Biochem. 2021, 158, 53-64. [CrossRef] [PubMed]

3. Corwin, D.L. Climate change impacts on soil salinity in agricultural areas. Eur. J. Soil Sci. 2021, 72, 842-862. [CrossRef]

4. Patel, M.K.; Kumar, M.; Li, W.; Luo, Y.; Burritt, D.J.; Alkan, N.; Tran, L.-S.P. Enhancing salt tolerance of plants: From metabolic reprogramming to exogenous chemical treatments and molecular approaches. Cells 2020, 9, 2492. [CrossRef] [PubMed]

5. Ashraf, M. Relationships between growth and gas exchange characteristics in some salt-tolerant amphidiploid Brassica species in relation to their diploid parents. Environ. Exp. Bot. 2001, 45, 155-163. [CrossRef]

6. Chakraborty, K.; Bose, J.; Shabala, L.; Eyles, A.; Shabala, S. Evaluating relative contribution of osmotolerance and tissue tolerance mechanisms toward salinity stress tolerance in three Brassica species. Physiol. Plant. 2016, 158, 135-151. [CrossRef] [PubMed]

7. Pavlović, I.; Mlinarić, S.; Tarkowská, D.; Oklestková, J.; Novák, O.; Lepeduš, H.; Vujčić Bok, V.; Radić Brkanac, S.; Strnad, M.; Salopek-Sondi, B. Early Brassica crops responses to salinity stress: A comparative analysis between Chinese cabbage, White cabbage and Kale. Front. Plant Sci. 2019, 10, 450. [CrossRef]

8. Van Zelm, E.; Zhang, Y.; Testerink, C. Salt tolerance mechanisms of plants. Ann. Rev. Plant Biol. 2020, 71, 403-433. [CrossRef]

9. Šamec, D.; Karalija, E.; Šola, I.; Vujčić Bok, V.; Salopek-Sondi, B. The role of polyphenols in abiotic stress response: The influence of molecular structure. Plants 2021, 10, 118. [CrossRef] [PubMed]

10. Sharma, A.; Shahzad, B.; Rehman, A.; Bhardwaj, R.; Landi, M.; Zheng, B. Response of phenylpropanoid pathway and the role of polyphenols in plants under abiotic stress. Molecules 2019, 24, 2452. [CrossRef]

11. Hasanuzzaman, M.; Nahar, K.; Fujita, M. Plant response to salt stress and role of exogenous protectants to mitigate salt-induced damages. In Ecophysiology and Responses of Plants under Salt Stress; Ahmad, P., Azooz, M., Prasad, M., Eds.; Springer Science \& Business Media: Berlin/Heidelberg, Germany; LLC: New York, NY, USA, 2013; pp. 25-87. [CrossRef]

12. Miura, K.; Tada, Y. Regulation of water, salinity, and cold stress responses by salicylic acid. Front. Plant Sci. 2014, 5, 4. [CrossRef] [PubMed]

13. Kaur, H.; Bhardwaj, R.D.; Grewal, S.K. Mitigation of salinity-induced oxidative damage in wheat (Triticum aestivum L.) seedlings by exogenous application of phenolic acids. Acta Physiol. Plant. 2017, 39, 221-236. [CrossRef]

14. Parvin, K.; Nahar, K.; Hasanuzzaman, M.; Bhuyan, M.B.; Mohsin, S.M.; Fujita, M. Exogenous vanillic acid enhances salt tolerance of tomato: Insight into plant antioxidant defense and glyoxalase systems. Plant Physiol. Biochem. 2020, 150, 109-120. [CrossRef] [PubMed]

15. Wan, Y.Y.; Zhang, Y.; Zhang, L.; Zhou, Z.Q.; Li, X.; Shi, Q.; Wang, X.J.; Bai, J.G. Caffeic acid protects cucumber against chilling stress by regulating antioxidant enzyme activity and proline and soluble sugar contents. Acta Physiol. Plant. 2015, 37, 1706-1715. [CrossRef]

16. El-Soud, W.A.; Hegab, M.M.; Elgawad, H.A.; Zinta, G.; Asard, H. Ability of ellagic acid to alleviate osmotic stress on chickpea seedlings. Plant Physiol. Biochem. 2013, 71, 173-183. [CrossRef] [PubMed]

17. Linić, I.; Šamec, D.; Grúz, J.; Vujčić Bok, V.; Strnad, M.; Salopek-Sondi, B. Involvement of phenolic acids in short-term adaptation to salinity stress is species specific among Brassicaceae. Plants 2019, 8, 155. [CrossRef] [PubMed]

18. Yusuf, M.A.; Kumar, D.; Rajwanshi, R.; Strasser, R.J.; Tsimilli-Michael, M.; Govindjee; Sarin, N.B. Overexpression of g-tocopherol methyl transferase gene in transgenic Brassica juncea plants alleviates abiotic stress: Physiological and chlorophyll a fluorescence measurements. Biochim. Biophys. Acta 2010, 1797, 1428-1438. [CrossRef] [PubMed]

19. Kalaji, H.M.; Baba, W.; Gediga, K.; Goltsev, V.; Samborska, I.A.; Cetner, M.D.; Karmowska, K. Chlorophyll fluorescence as a tool for nutrient status identification in rapeseed plants. Photosynth. Res. 2018, 136, 329-343. [CrossRef]

20. Dabrowski, P.; Baczewska-Dąbrowska, A.H.; Kalaji, H.M.; Goltsev, V.; Paunov, M.; Rapacz, M.; Wójcik-Jagła, M.; Pawluśkiewicz, B.; Baba, W.; Brestic, M. Exploration of chlorophyll a fluorescence and plant gas exchange parameters as indicators of drought tolerance in perennial ryegrass. Sensors 2019, 19, 2736. [CrossRef]

21. Mageney, V.; Neugart, S.; Albach, D.C. A guide to the variability of flavonoids in Brassica oleracea. Molecules 2017, $22,252$. [CrossRef] [PubMed]

22. Cartea, M.E.; Francisco, M.; Soengas, P.; Velasco, P. Phenolic compounds in Brassica vegetables. Molecules 2011, 16, 251-280. [CrossRef] [PubMed]

23. Gharsallah, C.; Fakhfakh, H.; Grubb, D.; Gorsane, F. Effect of salt stress on ion concentration, proline content, antioxidant enzyme activities and gene expression in tomato cultivars. AOB Plants 2016, 8, plw055. [CrossRef] [PubMed]

24. Hayat, S.; Hayat, Q.; Alyemeni, M.N.; Wani, A.S.; Pichtel, J.; Ahmad, A. Role of proline under changing environments. Plant Signal. Behav. 2012, 7, 1456-1466. [CrossRef]

25. Hayat, S.; Mir, B.A.; Wani, A.S.; Hasan, S.A.; Irfan, M.; Ahmad, A. Screening of salt-tolerant genotypes of Brassica juncea based on photosynthetic attributes. J. Plant Interact. 2011, 6, 53-60. [CrossRef]

26. Maurya, D.K.; Devasagayam, T.P.A. Antioxidant and prooxidant nature of hydroxycinnamic acid derivatives ferulic and caffeic acids. Food Chem. Toxicol. 2010, 48, 3369-3373. [CrossRef] [PubMed]

27. Li, D.-M.; Nie, Y.-X.; Zhang, J.; Yin, J.-S.; Li, Q.; Wang, X.-J.; Bai, J.-G. Ferulic acid pretreatment enhances dehydration-stress tolerance of cucumber seedlings. Biol. Plant. 2013, 57, 711-717. [CrossRef] 
28. Cheng, Z.-Y.; Sun, L.; Wang, X.-J.; Sun, R.; An, Y.-Q.; An, B.-L.; Zhu, M.-X.; Zhao, C.-F.; Bai, J.-G. Ferulic acid pretreatment alleviates heat stress in blueberry seedlings by inducing antioxidant enzymes, proline, and soluble sugars. Biol. Plant. 2018, 62, 534-542. [CrossRef]

29. Pavlović, I.; Petř́k, I.; Tarkowska, D.; Lepeduš, H.; Vujčić, V.; Radić Brkanac, S.; Novák, O.; Salopek-Sondi, B. Correlations between phytohormones and drought tolerance in selected Brassica crops: Chinese cabbage, white cabbage and kale. Int. J. Mol. Sci. 2018, 19, 2866. [CrossRef] [PubMed]

30. Mohamed, I.A.A.; Shalby, N.; Bai, C.; Qin, M.; Agami, R.A.; Jie, K.; Wang, B.; Zhou, G. Stomatal and photosynthetic traits are associated with investigating sodium chloride tolerance of Brassica napus L. cultivars. Plants 2020, 9, 62. [CrossRef] [PubMed]

31. Khan, M.I.R.; Fatma, M.; Per, T.S.; Anjum, N.A.; Khan, N.A. Salicylic acid-induced abiotic stress tolerance and underlying mechanisms in plants. Front. Plant Sci. 2015, 6, 462. [CrossRef] [PubMed]

32. Hniličková, H.; Hnilička, F.; Martinková, J.; Kraus, K. Effects of salt stress on water status, photosynthesis and chlorophyll fluorescence of rocket. Plant Soil Environ. 2017, 63, 362-367. [CrossRef]

33. Oukarroum, A.; Bussotti, F.; Goltsev, V.; Kalaji, H.M. Correlation between reactive oxygen species production and photochemistry of photosystems I and II in Lemna gibba L. plants under salt stress. Environ. Exp. Bot. 2015, 109, 80-88. [CrossRef]

34. Syeed, S.; Anjum, N.A.; Nazar, R.; Iqbal, N.; Masood, A.; Khan, N.A. Salicylic acid-mediated changes in photosynthesis, nutrients content and antioxidant metabolism in two mustard (Brassica juncea L.) cultivars differing in salt tolerance. Acta Physiol. Plant. 2011, 33, 877-886. [CrossRef]

35. Hussain, M.I.; Reigosa, M.J. Secondary metabolites, ferulic acid and p-hydroxybenzoic acid induced toxic effects on photosynthetic process in Rumex acetosa L. Biomolecules 2021, 11, 233. [CrossRef] [PubMed]

36. Salvatori, E.; Fusaro, L.; Strasser, R.J.; Bussotti, F.; Manes, F. Effects of acute O3 stress on PSII and PSI photochemistry of sensitive and resistant snap bean genotypes (Phaseolus vulgaris L.), probed by prompt chlorophyll "a" fluorescence and $820 \mathrm{~nm}$ modulated reflectance. Plant Physiol. Biochem. 2015, 97, 368-377. [CrossRef] [PubMed]

37. Ceppi, M.G.; Oukarroum, A.; Çiçek, N.; Strasser, R.J.; Schansker, G. The IP amplitude of the fluorescence rise OJIP is sensitive to changes in the photosystem I content of leaves: A study on plants exposed to magnesium and sulfate deficiencies, drought stress and salt stress. Physiol. Plant. 2012, 144, 277-288. [CrossRef] [PubMed]

38. Horváth, E.; Csiszár, J.; Gallé, Á.; Poór, P.; Szepesi, Á.; Tari, I. Hardening with salicylic acid induces concentration-dependent changes in abscisic acid biosynthesis of tomato under salt stress. J. Plant Physiol. 2015, 183, 54-63. [CrossRef] [PubMed]

39. Husen, A.; Iqbal, M.; Sohrab, S.S.; Ansari, M.K.A. Salicylic acid alleviates salinity-caused damage to foliar functions, plant growth and antioxidant system in Ethiopian mustard (Brassica carinata A. Br.). Agric. Food Secur. 2018, 7, 44. [CrossRef]

40. Hura, T.; Hura, K.; Grzesiak, S. Possible contribution of cell-wall-bound ferulic acid in drought resistance and recovery in triticale seedlings. J. Plant Physiol. 2009, 166, 1720-1733. [CrossRef] [PubMed]

41. Ma, X.; Xia, H.; Liu, Y.; Wei, H.; Zheng, X.; Song, C.; Chen, L.; Liu, H.; Luo, L. Transcriptomic and metabolomic studies disclose key metabolism pathways contributing to well-maintained photosynthesis under the drought and the consequent drought-tolerance in rice. Front. Plant Sci. 2016, 7, 1886. [CrossRef] [PubMed]

42. Buhmann, A.; Papenbrock, J. An economic point of view of secondary compounds in halophytes. Funct. Plant Biol. 2013, 40, 952-967. [CrossRef] [PubMed]

43. Oliva, M.; Guy, A.; Galili, G.; Dor, E.; Schweitzer, R.; Amir, R.; Hacham, Y. Enhanced production of aromatic amino acids in tobacco plants leads to increased phenylpropanoid metabolites and tolerance to stresses. Front. Plant Sci. 2021, 11, 604349. [CrossRef] [PubMed]

44. Yan, K.; Zhao, S.; Bian, L.; Chen, X. Saline stress enhanced accumulation of leaf phenolics in honeysuckle (Lonicera japonica Thunb.) without induction of oxidative stress. Plant Physiol. Biochem. 2017, 112, 326-334. [CrossRef] [PubMed]

45. Martinez, V.; Mestre, T.C.; Rubio, F.; Girones-Vilaplana, A.; Moreno, D.A.; Mittler, R.; Rivero, R.M. Accumulation of flavonols over hydroxycinnamic acids favors oxidative damage protection under abiotic stress. Front. Plant Sci. 2016, 7, 838. [CrossRef] [PubMed]

46. Minh, L.T.; Khang, D.T.; Ha, P.T.T.; Tuyen, P.T.; Minh, T.N.; Quan, N.V.; Xuan, T.D. Effects of salinity stress on growth and phenolics of rice (Oryza sativa L.). Int. Lett. Nat. Sci. 2016, 57, 1-10. [CrossRef]

47. Santangeli, M.; Capo, C.; Beninati, S.; Pietrini, F.; Forni, C. Gradual exposure to salinity improves tolerance to salt stress in rapeseed (Brassica napus L.). Water 2019, 11, 1667. [CrossRef]

48. Šamec, D.; Linić, I.; Salopek-Sondi, B. Salinity stress as an elicitor for phytochemicals and minerals accumulation in selected leafy vegetables of Brassicaceae. Agronomy 2021, 11, 361. [CrossRef]

49. Singh, P.; Arif, Y.; Bajguz, A.; Hayat, S. The Role of Quercetin in Plants. Authorea 2021. (preprint). [CrossRef]

50. Parvin, K.; Hasanuzzaman, M.; Bhuyan, M.H.M.B.; Mohsin, S.M.; Fujita, M. Quercetin mediated salt tolerance in tomato through the enhancement of plant antioxidant defense and glyoxalase systems. Plants 2019, 8, 247. [CrossRef] [PubMed]

51. Hou, M.; Zhang, Y.; Mu, G.; Cui, S.; Yang, X.; Liu, L. Molecular cloning and expression characterization of flavonol synthase genes in peanut (Arachis hypogaea). Sci. Rep. 2020, 10, 17717. [CrossRef] [PubMed]

52. Li, X.; Zhang, L.-P.; Zhang, L.; Yan, P.; Ahammed, G.J.; Han, W.-Y. Methyl salicylate enhances flavonoid biosynthesis in tea leaves by stimulating the phenylpropanoid pathway. Molecules 2019, 24, 362. [CrossRef]

53. Strasser, R.J.; Tsimilli-Michael, M.; Srivastava, A. Analysis of the chlorophyll a fluorescence transient. In Chlorophyll a Fluorescence: A Signature of Photosynthesis; Papageorgiou, G.C., Govindjee, Eds.; Springer: Dordrecht, The Netherlands, 2004; Volume 19, pp. 321-362. 
54. Singleton, V.L.; Rossi, J.A. Colorimetry of total phenolics witphosphomolybdic-phosphotungstic acid reagents. Am. J. Enol. Vitic. 1965, 16, 144-158.

55. Council of Europe. European Pharmacopoeia, 4th ed.; Council of Europe: Strasbourg, France, 2004; pp. $2377-2378$.

56. Zhishen, J.; Mengcheng, T.; Jianming, W. The determination of flavonoid contents in mulberry and their scavenging effects on superoxide radicals. Food Chem. 1999, 64, 555-559. [CrossRef]

57. Kusznierewicz, B.; Bartoszek, A.; Wolska, L.; Drzewiecki, J.; Gorinstein, S.; Namiésnik, J. Partial characterization of white cabbages (Brassica oleracea var. capitata f. alba) from different regions by glucosinolates, bioactive compounds, total antioxidant activities and proteins. LWT-Food Sci. Technol. 2008, 41, 1-9. [CrossRef]

58. Benzie, I.F.F.; Strain, J.J. Ferric reducing/antioxidant power assay: Direct measure of total antioxidant activity of biological fluids and modified version for simultaneous measurement of total antioxidant power and ascorbic acid concentration. Meth. Enzymol. 1999, 299, 15-27.

59. Brand-Williams, W.; Cuvelier, M.E.; Berset, C. Use of a free radical method to evaluate antioxidant activity. LWT-Food Sci. Technol. 1995, 28, 25-30. [CrossRef]

60. Šamec, D.; Kruk, V.; Ivanišević, P. Influence of seed origin on morphological characteristics and phytochemicals levels in Brassica oleracea var. acephala. Agronomy 2019, 9, 502. [CrossRef]

61. Heath, R.L.; Packer, L. Photoperoxidation in isolated chloroplasts. I. Kinetics and stoichiometry of fatty acid peroxidation. Arch. Biochem. Biophys. 1968, 125, 189-198. [CrossRef] 